\title{
Hantzsch-Type Dihydropyridines and Biginelli-Type Tetra- hydropyrimidines: A Review of their Chemotherapeutic Activities
}

\author{
Saghi Sepehri ${ }^{1}$, Horacio Perez Sanchez ${ }^{2}$, Afshin Fassihi ${ }^{1,2}$ \\ ${ }^{1}$ Department of Medicinal Chemistry, School of Pharmacy and Pharmaceutical Sciences, Isfahan University of Medical \\ Sciences, Isfahan, Iran. ${ }^{2}$ Bioinformatics and High Performance Computing Research Group, Computer Science \\ Department, Universidad Católica San Antonio de Murcia (UCAM), Spain.
}

Received, December 9, 2014; Revised, January 6, 2015, Accepted, January 17, 2015; Published January 19, 2015.

\begin{abstract}
Years after the first report on 1,4-dihydropyridines (1,4-DHPs) and 1,2,3,4tetrahydropyrimidines (1,2,3,4-THPMs) appeared, they are revisited as plausible therapeutic agents. This is mainly due to the convenient methods that exist for their synthesis and the diverse pharmacologic properties that these scaffolds present. 1,4-Dihydropyridines and 1,2,3,4-tetrahydropyrimidines are usually regarded as analogous in several aspects. They are both prepared in multi-component reactions using very similar starting materials and synthesis protocols. This leads to common structural features between 1,4-DHPs and 1,2,3,4THPMs, as well several related biological effects. For example, they share many pharmacological features such as analgesic, anti-tumor, antioxidant, anti-inflammatory, antitubercular, antibacterial, cardiovascular and adrenoceptor blocking activities. Numerous reviews have been devoted to the chemistry and cardiovascular effects of these compounds. However, the lack of a comprehensive literature overview on the chemotherapeutic ability of these scaffolds is behind the present attempt to provide a detailed survey of 1,4-DHPs and 1,2,3,4THPMs and their structural features as chemotherapeutic agents.
\end{abstract}

This article is open to POST-PUBLICATION REVIEW. Registered readers (see "For Readers") may comment by clicking on ABSTRACT on the issue's contents page.

\section{INTRODUCTION}

In the last two decades of the nineteenth century two analogous chemical scaffolds were introduced to organic chemistry, which were later to have a great impact on pharmacology and medicinal chemistry. Arthur Hantzsch in 1882, and Pietro Biginelli in 1893, reported methods for the synthesis of 1,4-dihydropyridine (1,4-DHP) and 1,2,3,4-tetrahydropyrimidine (1,2,3,4-THPM) structures, respectively, which now bear their names $(1,2)$. They were similar scaffolds in several aspects, each being prepared in a multi-component reaction (MCR), a very useful method in organic synthesis, which was still in its early years. Acetoacetate esters and aromatic aldehydes were the two components common in both reactions. This led to common structural features between 1,4DHPs and 1,2,3,4-THPMs, the latter of which could be regarded as the aza analogue of the former from a structural point of view. After years of being neglected, both these chemical scaffolds attracted considerable attention by medicinal chemists in the last three decades of the twentieth century. This was due to their diverse pharmacologic properties, which included analgesic $(3,4)$ anti-tumor $(5-7)$, antioxidant $(8,9)$, anti-inflammatory $(10,11)$, antitubercular (12,13), cardiovascular $(14,15)$, adrenoceptor blocking (16), and antibacterial $(17,18) \quad$ activities. Nonetheless, 1,4dihydropyridines are mostly known for their cardiovascular effects because, since their introduction into clinical practice in 1975, they have primarily been used as calcium channel modulators (19). 1,2,3,4-Tetrahydropyrimidines have also been evaluated as calcium channel modulating agents due to their structural similarity to 1,4dihydropyridines (20), and several reviews have been devoted to the chemistry and synthesis of these two chemical scaffolds (21-35). The calcium channel modulating activity of both scaffolds has also led to numerous reviews dedicated to biological responses initiated by this property (36-

\footnotetext{
Corresponding Author: Afshin Fassihi, Department of Medicinal Chemistry, School of Pharmacy and Pharmaceutcal Sciences, Isfahan University of Medical Sciences, Isfahan, Iran; E-mail: fassihi@pharm.mui.ac.ir
} 
51). However, little is about other biological capacities of 1,4-DHPs and 1,2,3,4-THPMs (5257).

In this review, we provide a literature overview on the chemotherapeutic ability of these two scaffolds. A detailed survey of the antitubercular, antibacterial, antifungal and cytotoxic activities described for 1,4-dihydropyridine and 1,2,3,4tetrahydropyrimidine analogues, from 2001 to the present is made. Since the general methods for the synthesis of these scaffolds, known as the Biginelli and Hantzsch reactions, and different strategies for the preparation of the more complicated derivatives have been discussed in several reviews, nothing is provided here about this subject and only their pharmacological properties are discussed.

\section{1,4-DIHYDROPYRIDINES}

\section{ANTITUBERCULAR ACTIVITY}

Somebody somewhere in the world is newly infected with tuberculosis (TB) bacilli every second and one-third of the world's population currently suffers from this disease. An estimated 1.5 million people die from TB each year (58).

Tuberculosis is principally caused by Mycobacterium tuberculosis, a remarkably successful airborne pathogen (59). The infection spreads through the air, but is both preventable and curable. The major solution to the problem is chemotherapy, which requires the development of effective and non-toxic antitubercular agents. The emergence of multi-drug resistance (MDR) has forced the development of new structural classes of antitubercular agents, several of which have shown promising activity. In this respect, 1,4dihydropyridines and 1,2,3,4-tetrahydropyrimidines are excellent starting scaffolds for the development of antiTB agents against the best-characterized strain of Mycobacterium tuberculosis, $\mathrm{H}_{37} \mathrm{Rv}$ (6062).

The first report of 1,4-dihydropyridine as an antitubercular scaffold dates back to 2001, when
Desai et al. described the high antitubercular activity for of 1,4-dihydropyridine 3,5dicarboxamide and 3,5-dicarboxylate ester derivatives (63). Since that time, it has been demonstrated that some features of dihydropyridine substituents have important effects on the antiTB activity of these compounds. The most studied features are the type of C-3, C-4 and C-5 substituents and also the lipophilicity of the compound. Most of the reported antitubercular 1,4DHPs fall into one of the three structural categories shown in Figure 1.

The first antitubercular 1,4-DHPs introduced were 3,5-dicarboxamide derivatives rather than 3,5dicarboxylate esters, which had been known as antihypertensive agents for decades (63). Other researchers identified more antitubercular derivatives of this scaffold $(12,64,65)$. Asymmetric 1,4-DHPs bearing one carboxylate ester group and symmetric analogues with carboxylate ester groups in both $\mathrm{C}-3$ and $\mathrm{C}-5$ positions were also reported as potent antitubercular agents $(62,66-68), \mathrm{C}-3$ and C5 derivatives in most cases being a (substituted) phenylcarboxamide moiety. There are also some reports of using heteroaromatic carboxamides in these positions $(12,69)$. In C-4 position, substituted phenyl $(61,63,66,69)$ and several heteroaromatic rings $(12,62,64,67,68,70)$ have been studied. N-1 (substituted) phenyl substitutions exist in the structure of some of the antitubercular 1,4-DHPs $(61,62,68)$.

Lipophilicity seems to be an important property since the microorganism cell wall is lipophilic in character and C-3, C-4 and C-5 substituents provide the necessary lipophilicity to the compounds. These positions are always substituted by lipophilic aromatic moieties. It is believed that phenyl substituted 3,5-dicarboxamides are in fact lipophilic prodrugs of the active dicarboxylic derivatives which cannot easily pass through the cell wall (63). The 3,5-dicarboxamide groups undergo hydrolysis to the parent dicarboxylic acid derivatives at the site of action (12,61-70).<smiles>CCCCCCNC(=O)C1=C(C)NC(C)=C(C(=O)NCC)C1Br</smiles><smiles>[R20]C(=O)C1=C(C)NC(C)=C(C(=O)N[GaH])C1Br</smiles><smiles>[R20]C(=O)C1=C(C)NC(C)=C(C([R])=O)C1[Al]</smiles>

Figure 1. Structural categories of antitubercular 1,4-DHPs 
Kharkar et al. (70) concluded that ortho substitution on the $\mathrm{C}-3$ and $\mathrm{C}-5$ phenyl moieties sterically reduce the rate of amide bond hydrolysis, decreasing the antitubercular activity of the compound. Examples of this are $\mathbf{1 a}$ and $\mathbf{1 b}$, the former compound being substantially more active than the latter (12) Figure 2.<smiles>[R]c1ccc(NC(=O)C2=C(C)NC(C)=C(C(=O)Nc3ccccc3)C2c2cnc(SC)n2[X]c2ccccc2)cc1</smiles>

\begin{tabular}{lcc}
\multicolumn{1}{c}{$\mathbf{X}$} & $\mathbf{R}$ & $\mathbf{M I C}^{\boldsymbol{a}}(\boldsymbol{\mu g} / \mathbf{m L})$ \\
1a $\mathrm{CH}_{2}$ & $p-\mathrm{ClC}_{6} \mathrm{H}_{5}$ & 1 \\
1b $\mathrm{CH}_{2}$ & $o-\mathrm{ClC}_{6} \mathrm{H}_{5}$ & $>16$ \\
Rifampicin & 1 \\
Isoniazide & 0.2
\end{tabular}

${ }^{a} \mathrm{MIC}=$ Minimum Inhibitory Concentration

Figure 2. Chemical structures and antitubercular activities of $\mathbf{1 a}$ and $\mathbf{1 b}$

Other examples can be found in the report provided by Manvar et al. (61). Compound 2a with ortho-Cl is less active than $\mathbf{2 b}$ with meta-Cl (Figure 3).<smiles>[R][R]1ccc(NC(=O)C2=C(C)NC(C)=C(C(=O)Nc3ccccc3)C2c2cc[R1]([R])cc2)cc1</smiles>

2a $\quad o-\mathrm{Cl} \quad o-\mathrm{Cl} \quad\left(\mathrm{PI}^{a}\right.$ at $\left.>12.5 \mu \mathrm{g} / \mathrm{mL}=11\right)$

2b $\quad m-\mathrm{Cl} \quad o-\mathrm{Cl} \quad$ (PI at $>6.25 \mu \mathrm{g} / \mathrm{mL}=72$ )

Rifampicin (PI at $>6.25 \mu \mathrm{g} / \mathrm{mL}=97$ )

${ }^{a} \mathrm{PI}=$ Percentage of Inhibition

Figure 3. Chemical structures and PIs (\%) of $\mathbf{2 a}$ and $\mathbf{2 b}$
Kharkar et al. (70) also concluded that electronwithdrawing groups in meta and para positions of the $\mathrm{C}-3$ and $\mathrm{C}-5$ phenyl carboxamide moieties increase the antiTB potency. This is not exemplified well in their report but a good example can be seen in other reports. 3a (PI at $2.5 \mu \mathrm{g} / \mathrm{mL}=98)$ and $\mathbf{3 b}$ (PI at $2.5 \mu \mathrm{g} / \mathrm{mL}=97$ ) are meta/para nitro phenyl compounds with high antitubercular activity as indicated in (70) Figure 4.

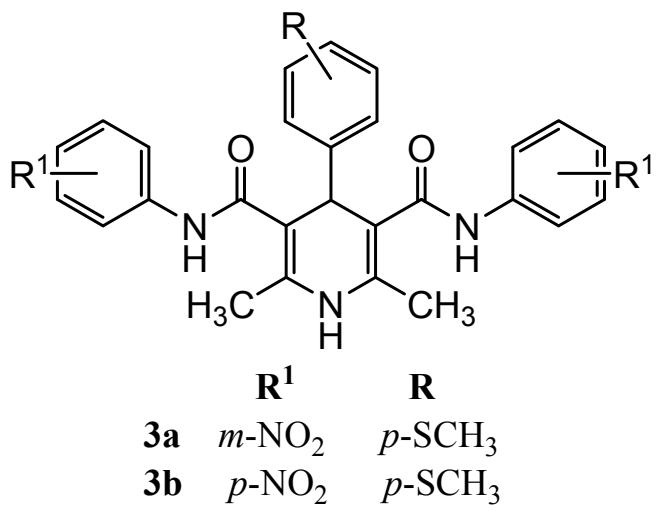

Figure 4. Chemical structures of $\mathbf{3 a}$ and $\mathbf{3 b}$

It is interesting that $\mathbf{2 c}$ with para-Cl is also very weak compared with $\mathbf{2 b}$ with its meta-Cl substitution (61) Figure 5. The reason is that the chloro group in para position is an electronreleasing rather electron-withdrawing group, while the chloro group in meta position is electronwithdrawing.

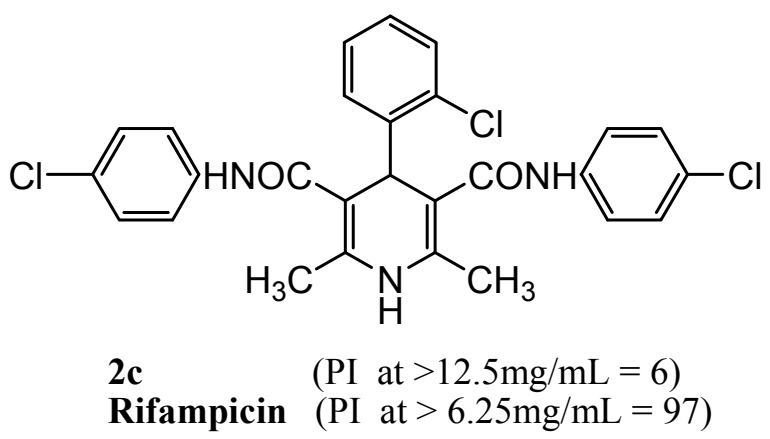

Figure 5. Structure and antitubercular activity of compound 2c

Asymmetric 3,5-dicarboxamide 1,4-dihydropyridines with two different dicarboxamide derivatives have also been evaluated as antiTB agents but, compared to the symmetric equivalents, they show weaker activity (61). Asymmetric 1,4- 
DHPs bearing a carboxylate ester and a dicarboxamide group have also been studied for antitubercular activity as mentioned above. Khoshneviszadeh et al. (67) introduced into alkyl (4a-e) or aralkyl (4f-j) esters to 1,4dihydropyridines substituted with one carboxamide group at the C-5 position (Figure 6).

Aralkyl esters were found to be more potent, with a potency that depended on the number of methylen groups they contained in the aralkyl ester group. Benzyl, phenethyl and phenpropyl esters were most potent and further increases in the length of the chain led to a fifty percent reduction of the activity (67). This can be explained by the effect of the optimum lipophilicity on the potency (discussed below). Although alkyl esters were weaker antitubercular agents, they showed the same relationship between potency and lipophilicity.

Optimum lipophilicity is probably necessary for the compound to become an active antiTB agent, as was suggested by Kharkar et al. (70), who developed 3D-quantitative structure-activity relationship (3D-QSAR) models, and observed that the parameter CLogP had no effect on the significance of the CoMFA and CoMSIA models obtained. Compound 3c (PI at $2.5 \mu \mathrm{g} / \mathrm{mL}=98$ ) was less lipophilic than 3d (PI at $2.5 \mu \mathrm{g} / \mathrm{mL}=11$ ) Figure 7 , confirming that the third chloro group in the latter compound does not have a positive effect on the antiTB activity $(6,14)$. Compound $\mathbf{3 e}$, which was even less lipophilic than 3c, showed high antitubercular activity (PI at $2.5 \mu \mathrm{g} / \mathrm{mL}=94$ ).

In the same vein, compound $\mathbf{4 j}(\mathrm{MIC}=2$ $\mu \mathrm{g} / \mathrm{mL})$, with its higher $\operatorname{LogP}(2.23$ vs 0.79$)$ than compound $4 \mathbf{f}(\mathrm{MIC}=1 \mu \mathrm{g} / \mathrm{mL})$ had half of its antitubercular activity (68) Figure 6. Thus, besides this physicochemical property, other structural features also determine the potency; for example, the effect of the polar electron-withdrawing nitro groups substituted on the C-3 and C-5 phenyl carboxamide moieties discussed above $(61,70)$.

Analysis of the structure of the antiTB 1,4DHPs reported by Fassihi et al. (12) revealed that replacing the $\mathrm{NH}$ moiety with $\mathrm{CH}_{2}$ in the less lipophilic compound 1c increased its potency. Meta-Cl isomer 1d was much weaker, than the active para-isomer 1a. This is in contrast with the explanation of the differences between $\mathbf{2 b}$ and $\mathbf{2 c}$ activities (60) Figures 2,8, mentioned previously, which suggests that other factors are determinants of the potencies.<smiles>CCC(C)NC(=O)C1=C(C)NC(C)=C(C(=O)O[Ga])C1c1ncc([N+](=O)[O-])n1C</smiles>

Ar

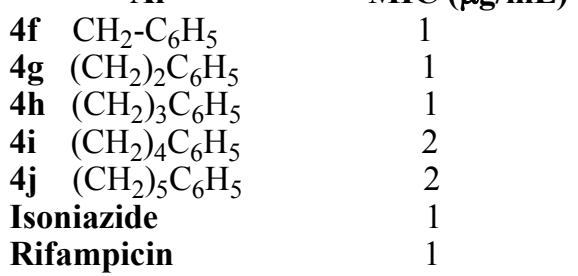

Figure 6. Chemical structures and MICs $(\mu \mathrm{g} / \mathrm{mL})$ of asymmetric 1,4-dihydropyridines 


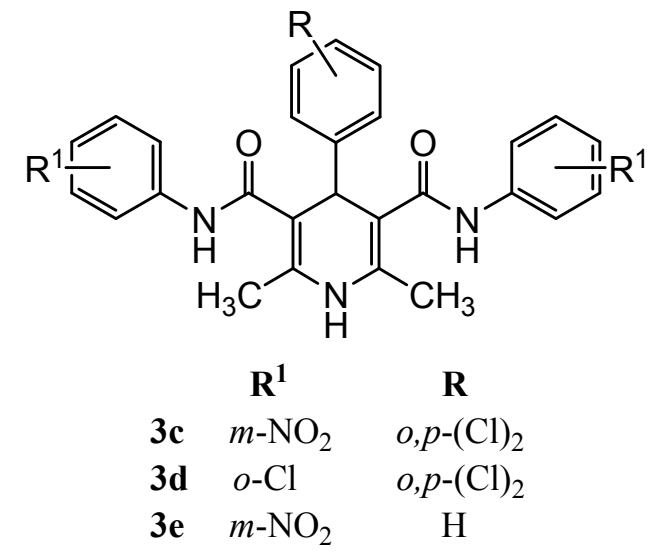

Figure 7. Structures of 3c-e<smiles>[R]c1ccc(NC(=O)C2=C(C)NC(C)=C(C(=O)Nc3ccccc3)C2c2cnc(SC)n2[X]c2ccccc2)cc1</smiles>

\begin{tabular}{|c|c|c|}
\hline $\mathbf{X}$ & $\mathbf{R}$ & MIC $(\mu \mathrm{g} / \mathrm{mL})$ \\
\hline 1c $\mathrm{NH}$ & $p-\mathrm{ClC}_{6} \mathrm{H}_{5}$ & $>16$ \\
\hline $\mathrm{CH}_{2}$ & $m-\mathrm{ClC}_{6} \mathrm{H}_{5}$ & $>16$ \\
\hline Rifampici & & 1 \\
\hline Isoniazide & & 0.2 \\
\hline
\end{tabular}

Figure 8. Chemical structures and MICs of $\mathbf{1 c}$ and 1d

The presence of different aromatic moieties at the $\mathrm{C}-4$ position of the dihydropyridine ring has been seen to affect the antiTB activity, partly by providing the desired lipophilicity to the molecule $(62,64,65,67,68,70)$. Phenyl substituted groups were the first aromatic moieties evaluated in this position $(61,63,66)$. Compound 3f $(\log P=-0.3888)$ was reported to be less reactive than $\mathbf{3 g}$ with a $\operatorname{LogP}$ of 1.1949 , confirming the effect of the lipophilicity on the potency $(63,70)$ Figure 9.

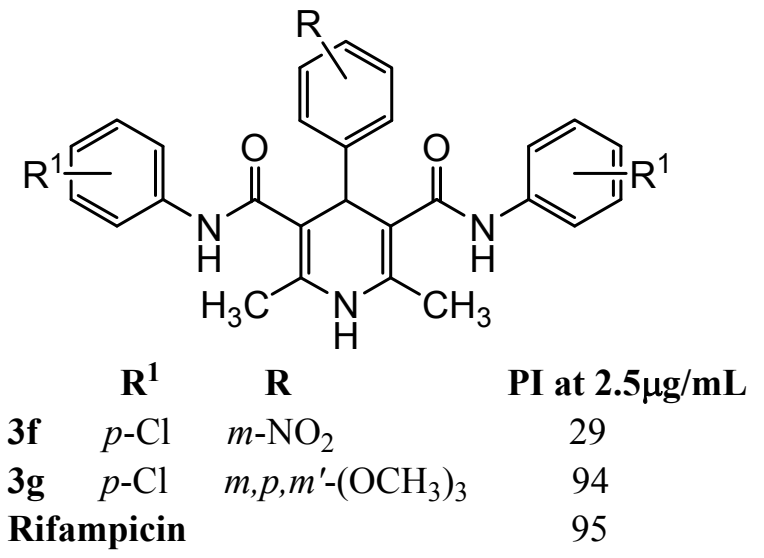

Figure 9. Structure and antitubercular activity (PI) of $\mathbf{3 f}$ and $\mathbf{3 g}$

Here again some controversy exists between the different reports, confirming the involvement of other factors as stated previously. For example, 2d with one more nitro group in its structure was more potent than $2 \mathrm{e}$ and even more potent than $\mathbf{2 f}$ and $\mathbf{2 g}$ (PIs at $>6.25 \mu \mathrm{g} / \mathrm{mL}=64,42,29$ and 28, respectively), which contain halogen atoms in their structures (61) Figure 10.<smiles>[R][R]1ccc(NC(=O)C2=C(C)NC(C)=C(C(=O)Nc3ccccc3)C2c2cc[R]([R])cc2)cc1</smiles>

Figure 10. Chemical structures of $\mathbf{2 d - g}$

Presumably some kinds of electrostatic interactions or hydrogen bonding is involved in the attachment of the molecule to its site of action. According to a 3D-QSAR study published by Kharkar et al. (70), the presence of para substituents with rotatable bonds at the C-4 
position, such as $-\mathrm{N}\left(\mathrm{CH}_{3}\right)_{2},-\mathrm{OCH}_{3}$ and $-\mathrm{SCH}_{3}$, increases antiTB activity. The authors assumed the involvement of proper hydrogen bonding between these substituents and the receptor due to the free rotation of these substituents (70). This finding was confirmed by Manvar et al. (61) in a more recent 3D-QSAR study. Some disagreement concerning this relationship can be observed in the experimental data, again suggesting that other factors are determining the potency of the compounds. For example, $\mathbf{2 h}$ and $\mathbf{2 i}$ (PIs at $>12.5$ $\mu \mathrm{g} / \mathrm{mL}=93$ and 84 , respectively) were strong compounds but, $2 \mathbf{j}$ (PI at $>12.5 \mu \mathrm{g} / \mathrm{mL}=23$ ) was weak, although all had a para-dimethylamino phenyl group at the C-4 position with slight differences in other substituents (61). In the case of the methoxy group in this position, most of the compounds were weak: $2 \mathbf{k}$ (PI at $>12.5 \mu \mathrm{g} / \mathrm{mL}=$ 30) was weak and $2 \mathrm{l}(\mathrm{PI}$ at $>6.25 \mu \mathrm{g} / \mathrm{mL}=71$ ) has been shown to be a moderate antitubercular agent (Figure 11). Several weak examples can be extracted from the data provided by Manvar et al. (61).The lack of the data for defining the resonance or inductive effects of the substituents on the C-3 and $\mathrm{C}-5$ phenyl moieties makes it difficult to establish a relationship between the effect of the above-mentioned C-4 substitutions and the antitubercular activity. The assumption made by Kharkar et al. (70) that the ortho substitution on the C-3 and C-5 phenyl moieties sterically reduces the rate of amide bond hydrolysis could be an explanation for the weak antitubercular activities of some of these compounds.

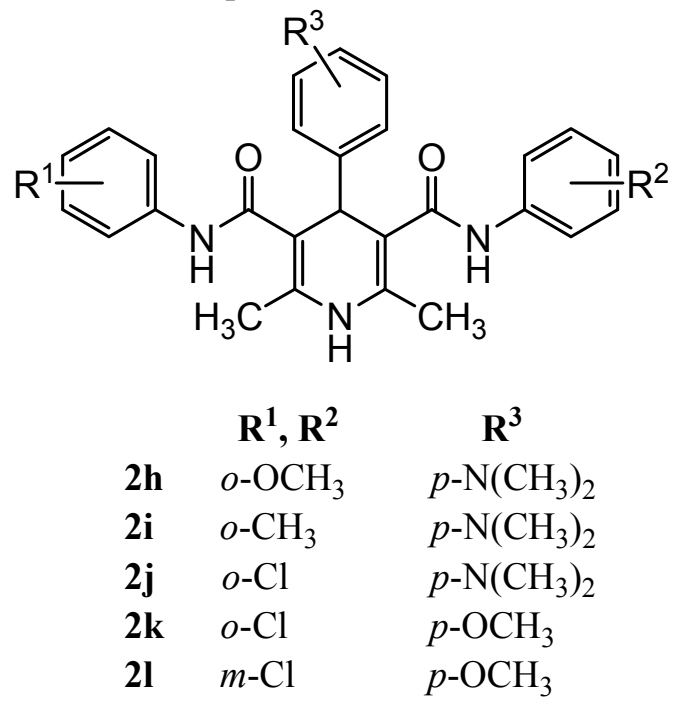

N-1 substitution of the 1,4-dihydropyridine 3,5dicarboxylate esters with (substituted) phenyl moiety $\mathbf{5 a}$ and $\mathbf{5 b}$ resulted in compounds with lower antiTB activity than unsubstituted compounds (61) Figure 12.

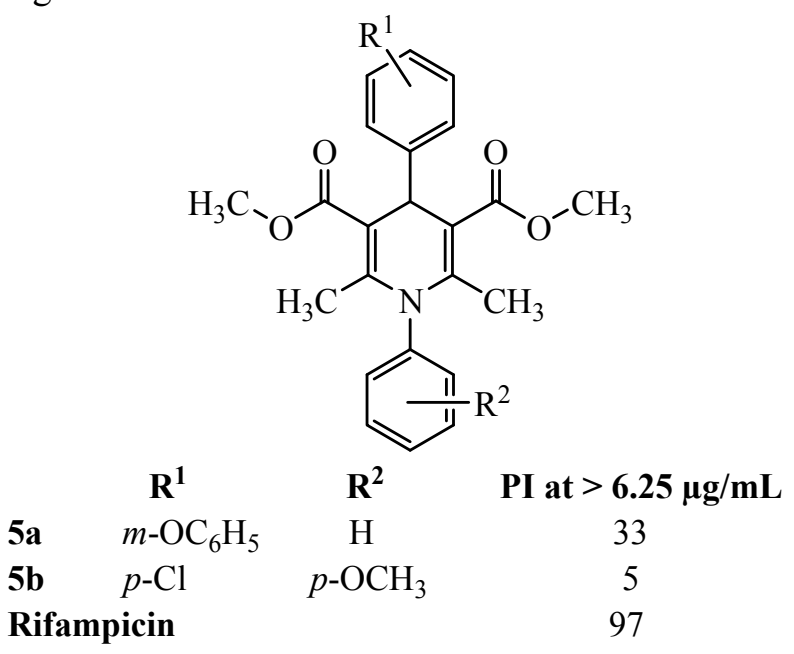

Figure 12. PIs of antitubercular N-1 substituted 1,4dihydropyridine 3,5-dicarboxylate esters

However, this cannot be regarded as a rule: for example, N-1 substitution (5) did not change the potency. This can be concluded by comparing the potencies of 6 and 7 (68) Figure 13.

In an attempt to suggest a putative mechanism of action for this class of antitubercular agents Mahnam et al. (71) focused on the structural similarities of the 1,4-dihydropyridine scaffold to $\mathrm{NADH}$, the coenzyme for a key regulatory enzyme in fatty acid elongation, trans-2-enoyl-ACP reductase. The authors determined the high binding affinity of a series of 1,4-dihydropyridine-3,5dicarboxamide derivatives to enoyl reductase from Mycobacterium tuberculosis using docking and molecular dynamics simulation methods. Using the same methods, they also obtained high binding affinity for the 3,5-dicarboxylic acid derivatives and concluded that aryl or heteroaryl substituents at C-3 and $\mathrm{C}-5$ are not necessary for receptor binding and only provide the necessary lipophilicity to the molecule. This agrees with the observations of Desai et al. and Kharkar et al. that carboxamide groups are hydrolyzed to 1,4-dihydropyridine-3,5carboxylic acid derivatives with antibuercular activity (12, 61-71).

Figure 11. Structures of $\mathbf{2 h - l}$ 
<smiles>CCOC(=O)C1=C(C)NC(C)=C(C(=O)OCC)C1c1cn(-c2ccccc2)nc1-c1ccccc1</smiles>

6

6

7

Isoniazide
MIC $(\mu \mathrm{g} / \mathrm{mL})$

1.56

1.56

0.03<smiles>CCOC(=O)C1=C(C)N(c2ccccc2)C(C)=C(C(=O)OCC)C1c1cn(-c2ccccc2)nc1-c1ccccc1</smiles>

PI at $1.56 \mu \mathrm{g} / \mathrm{mL}$

95

96

Figure 13. Comparison of the antitubercular activity of N-1 substituted and N-1 unsubstituted 1,4-dihydropyridines

\section{ANTIMICROBIAL ACTIVITY}

Despite the recent advances in medicine, antimicrobial chemotherapy still remains a problem in most developing and even developed countries. The narrow spectrum of activity of some antimicrobial drugs on the market and the many serious adverse effects reported explain the reasons for the failure of antimicrobial chemotherapy and why there is a search for more acceptable compounds. The inevitable emergence of resistant strains of pathological microorganisms and of the growing list of multi-drug resistant strains is another serious problem in clinical practice (72). Among the many different chemical scaffolds screened, 1,4-dihydropyridine compounds have attracted attention both as antimicrobial agents and MDR-reversing entities because of their ability to exert synergistic antibacterial effects in combination with known antibiotics (73-99). It has been demonstrated that the type of C-3, C-4 and C5 substituent and the lipophilicity of the molecule have important effects on the antimicrobial activity of 1,4-dihydropyridine compounds. Three structural categories are found among the antimicrobial 1,4DHPs as shown in Figure 14.

1,4-DHP derivatives containing diethyl carbamoyl and ester substituents at C-3 and C-5, and substituted aromatic or heteroaromatic ring at C-4 position have also been reported as potential antimicrobial agents (73-76). An N-1 (substituted) phenyl substitution exists in the structure of some of the antimicrobial 1,4-DHPs (96-99).

Maya et al. (75) concluded that the presence of a fused ring attached to the dihydropyridine ring through the $\mathrm{C} 2=\mathrm{C} 3$ bond of the dihydropyridine moiety decreases the antimicrobial activity of the compound. Examples of this type of dihydropyridine derivatives are $\mathbf{8 a}, \mathbf{8 b}$ and $\mathbf{8 c}$ (Figure 15).<smiles>CCCCCCCNC(=O)C1=C(C)NC(C)=C(C(=O)NCC)C1Br</smiles><smiles>[R20]C(=O)C1=C(C)NC(C)=C(C([R])=O)C1[Al]</smiles>

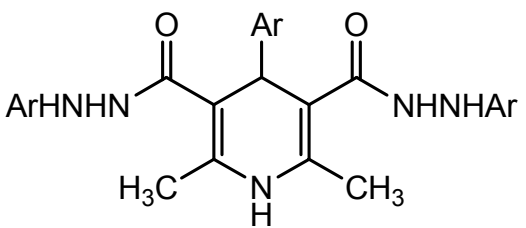

Figure 14. Three structural classes of antimicrobial 1,4-DHPs 
<smiles>COC(=O)C1=C(C)NC2=C(C(=O)CC(C)(C)C2)C1c1cccc(Cl)c1</smiles>

$8 \mathbf{a}$<smiles>COC(=O)C1=C(C)NC2=C(C(=O)CCC2)C1c1cccc(Cl)c1</smiles>

$\mathbf{8 b}$<smiles>CCOC(=O)C1=C(C)NC(C)=C(C(=O)OC)C1c1cccc(Cl)c1</smiles>

8c

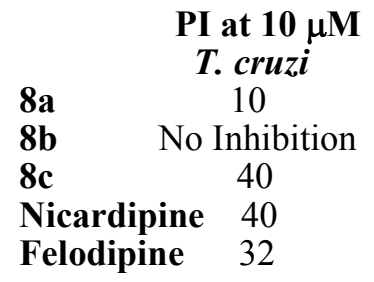

Figure 15. Chemical structures and antimicrobial activities of 8a-c

In addition, Ladani et al. (76) reported antimicrobial dihydropyridin derivatives as possessing two cyclic ketones fused to the main scaffold, instead of the C-3 and C-5 carboxylate derivatives. Compound 9a is an example with good fungicidal and poor bactericidal activity, while compound 10 (17) displayed good bactericidal properties (Figure 16).<smiles>O=C1CCCC2=C1C(C1Cc3ccccc3-n3nnnc31)C1=C(CCCC1=O)N2</smiles>

9a<smiles>COc1cc(C2C3=C(CCCC3=O)NC3=C2C(=O)CCC3)ccc1O</smiles>

10
Figure 16. Antimicrobial dihydropyridines with cyclic ketones fused to the main scaffold

Other examples were reported by Dabholkar et al. (77). Compounds 11a and 11b showed almost equal potency against Escherichia coli and very similar activities against Corynebacterium diphtheria (gram positive bacteria), Pseudomonas aeruginosa and Staphylococcus aureus (gram negative bacteria) to the reference drug, Ampicillin trihydrate (Figure 17).
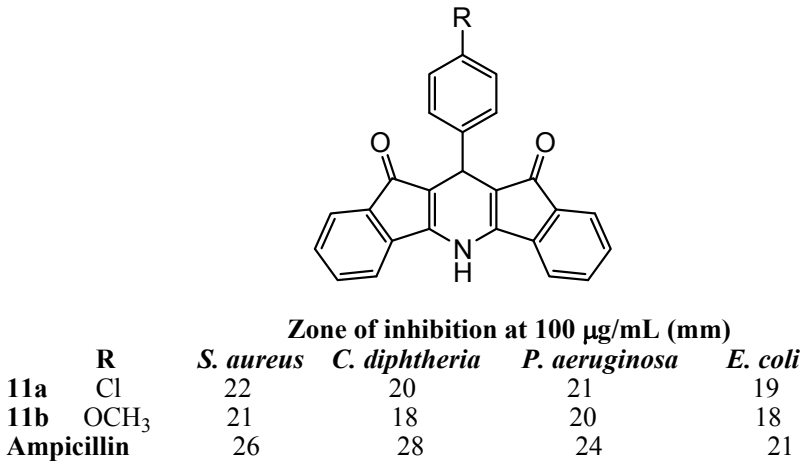

Figure 17. Chemical structures and zone of inhibition values (ZIs) of 11a and 11b

Ladani et al (76) and Gunduz et al. (78) prepared dihydropyridines with a fused cyclic ketone and a carboxylate or carboxamide moiety at the C-3 and C-5 positions of the DHP ring, finding the compounds to be antimicrobial agents $(\mathbf{9 b}, \mathbf{1 2 a}$ and 12b) (Figure 18).

Akbarzadeh et al. (79) in 2008 prepared antimicrobial 1,4-DHP 3,5-dicarboxamides, which were found to be inactive when used as antimicrobials alone, but active when used in conjunction with Amoxicillin. Comparison of the activities of the synthesized symmetrical amides indicated that the presence of withdrawing groups, especially at the para position of the phenyl carboxamide moieties, was essential enhancing activity; however, substitution at the meta or ortho 
positions reduced or eliminated this enhancing effect. 13a had no inhibitory activity against $S$.<smiles>COC(=O)C1=C(C)NC2=C(C(=O)CCC2)C1C1Cc2ccccc2-n2nnnc21</smiles>

9b<smiles>COC(=O)C1=C(C)NC2=C(C(=O)C(C)(C)CC2)C1c1cccc(F)c1F</smiles>

12a<smiles>CCN(CC)C(=O)C1=C(C)NC2=C(C(=O)CC(C)(C)C2)C1c1ccc(F)c(F)c1</smiles>

12b

Figure 18. 1,4-DHPs with a fused cyclic ketone and a carboxylate or carboxamide moiety at the C-3 and C-5 positions<smiles>CC1=C(C(=O)Nc2ccccc2Cl)C(c2cnc(SC(=O)O)n2C)C(C(=O)Nc2ccccc2Cl)=C(C)N1</smiles>

13a<smiles>CC1=C(C(=O)Nc2ccc(Cl)cc2)C(c2cnc(SC(=O)O)n2C)C(C(=O)Nc2ccc(Cl)cc2)=C(C)N1</smiles>

$13 b$

Zone of inhibitionat $25 \mu \mathrm{g} / \mathrm{mL}$ (mm)

13a+Amoxicillin 13b+Amoxicillin
S. aureus

No Inhibition

14

Figure 19. Chemical structures and antimicrobial activity of 13a and 13b in combination with Amoxicillin

The same research group in 2010 reported that disubstitution at meta and para positions of the phenylcarboxamide moieties with chlorine atoms also increased the activity, while the presence of an ortho- $\mathrm{Cl}$ substitution decreased the potency. This conclusion can be exemplified by compounds 14a and 14b in combination with Cloxacillin, whose joint antibacterial activities were studied against Methicillin-resistant S. aureus (MRSA) (80) Figure 20.

Sirisha et al. also demonstrated that 1,4-DHP3,5-dicarboxamides were more active than 1,4DHP-3,5-dicarboxylate esters. Most of the compounds they prepared were relatively more active against gram negative bacteria. Compound 15a was almost equipotent to Streptomycin/ Tetracyclin against gram negative bacteria [zone of inhibition $(\mathrm{ZI})=23,26$ and 25, 21 millimeters in 50 $\mu \mathrm{g} / \mathrm{mL}$ for Escherichia coli and Proteus vulgaris, respectively] (Figure 20). But, among the compounds they prepared, $\mathbf{1 5 b}$ was more potent against a gram positive bacterium, Bacillus subtilis, unlike other compounds. The ZI for this compound was $18 \mathrm{~mm}$ against $B$. subtilis (Tetracycline: 20 $\mathrm{mm}$ ) and 12 against $S$. aureus (Tetracycline: 22 $\mathrm{mm}$ ) both in $50 \mu \mathrm{g} / \mathrm{mL}$ (69) Figure 21.

Sirisha et al. reported on some more antibacterial 1,4-DHPs with higher activities against gram negative bacteria in 2011. For example, 16a and 16b had significant inhibitory activity against E. coli and P. vulgaris. 16a was also found to exhibit considerable activity against MRSA (81) Figure 22. Compounds with aromatic or heteroaromatic rings at $\mathrm{C}-3$ and C-5 arylcarboxamide moieties were active against the pathogenic microorganisms studied $(69,81)$.

The presence of bulk groups at C-3 and C-5 positions in some novel 1,4-dihydropyridines prepared by Rao et al. confirmed that lipophilicity is important for antimicrobial effects. Here again, 
the results obtained confirmed that compounds with a dicarboxylic acid ester moiety at C-3 and C-5 were less potent than dicarboxamide analogues (82). They also showed that 3,5- dicarboxamide compounds possessing a para substituent (-OH , $\mathrm{OCH}_{3}$ or $-\mathrm{Cl}$ ) on the $\mathrm{C}-4$ phenyl ring showed high inhibitory activities against gram positive and gram negative bacteria and fungi. For instance, 17a (ZI at $100 \mu \mathrm{g} / \mathrm{mL}=24 \mathrm{~mm}, \mathrm{ZI}$ for Ciprofloxacin $=23$ $\mathrm{mm}$ ) was found to be highly active against $S$. aureus. 17b (ZI at $100 \mu \mathrm{g} / \mathrm{mL}=26 \mathrm{~mm}$ ) was another potent compound against the same bacterium. 17b was also a good antifungal agent (ZI at $100 \mu \mathrm{g} / \mathrm{mL}=24 \mathrm{~mm}$ against Aspergillus niger, for Clotrimazole $=23$ ). Another compound of this series, 17c, showed high antifungal activity against Chrysosporium Sp. (82) Figure 23.

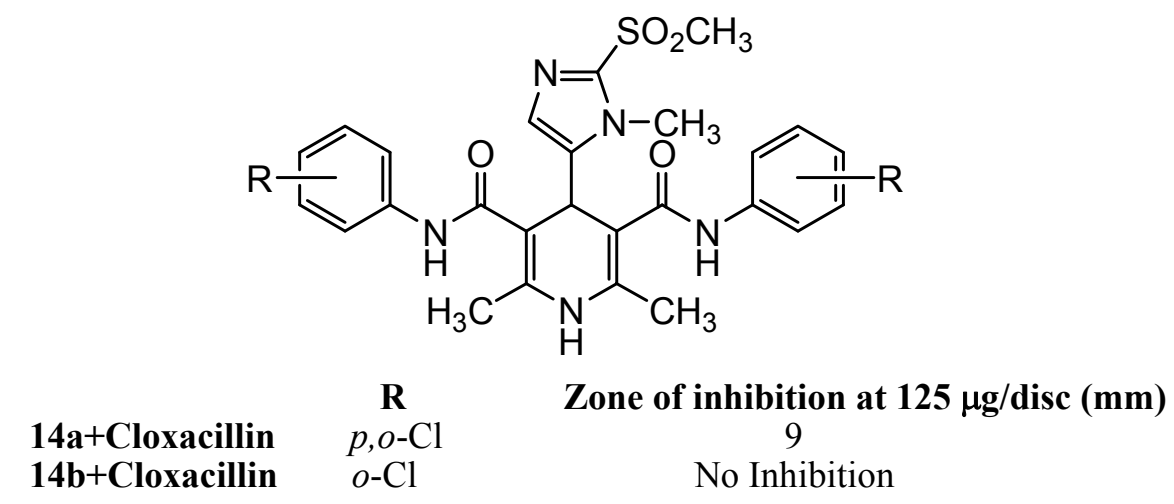

Figure 20. Chemical structures and antibacterial activities of $\mathbf{1 4 a}$ and $\mathbf{1 4 b}$ in combination with Cloxacillin<smiles>CC1=C(C(=O)Nc2ncccc2C)C(c2ccccn2)C(C(=O)Nc2ncccc2C)=C(C)N1</smiles>

$15 \mathbf{a}$<smiles>CC1=C(C(=O)Nn2c(C)nc3ccccc3c2=O)C(c2ncc[nH]2)C(C(=O)Nn2c(C)nc3ccccc3c2=O)=C(C)N1</smiles>

$15 b$

Figure 21. Chemical structures of $\mathbf{1 5 a}$ and $\mathbf{1 5 b}$ 
16a

Streptomycin Tetracyclin 16b

Streptomycin

Tetracyclin<smiles>CC1=C(C(=O)Nc2ccc(C)cc2)C(c2ccc[nH]2)C(C(=O)Nc2ccc(C)cc2)=C(C)N1</smiles>

E. coli

$22(50 \mu \mathrm{g} / \mathrm{mL})$ $23(50 \mu \mathrm{g} / \mathrm{mL})$ $25(50 \mu \mathrm{g} / \mathrm{mL})$
Zone of inhibition ( $\mathrm{mm}$ ) P. vulgaris $18(50 \mu \mathrm{g} / \mathrm{mL})$ $26(50 \mu \mathrm{g} / \mathrm{mL})$ $21(50 \mu \mathrm{g} / \mathrm{mL})$
MRSA

$10(1000 \mu \mathrm{g} / \mathrm{mL})$ $18(1000 \mu \mathrm{g} / \mathrm{mL})$ $15(1000 \mu \mathrm{g} / \mathrm{mL})$<smiles>CC1=C(C(=O)Nc2ccccc2C)C(c2ccccn2)C(C(=O)Nc2ccccc2C)=C(C)N1</smiles>

\section{E. coli}

$19(50 \mu \mathrm{g} / \mathrm{mL})$

$23(50 \mu \mathrm{g} / \mathrm{mL})$ $25(50 \mu \mathrm{g} / \mathrm{mL})$
Zone of inhibition (mm) $P$. vulgaris $16(50 \mu \mathrm{g} / \mathrm{mL})$ $26(50 \mu \mathrm{g} / \mathrm{mL})$ $21(50 \mu \mathrm{g} / \mathrm{mL})$
MRSA

$8(1000 \mu \mathrm{g} / \mathrm{mL})$

$18(1000 \mu \mathrm{g} / \mathrm{mL})$

$15(1000 \mu \mathrm{g} / \mathrm{mL})$

Figure 22. Antimicrobial activity of $\mathbf{1 6 a}$ and $\mathbf{1 6 b}$<smiles>[R]c1ccc(C2C(C(=O)Nc3cccc4ccccc34)=C(C)NC(C)=C2C(=O)Nc2cccc3ccccc23)cc1</smiles>
$17 \mathbf{a}$
R: $\mathrm{Cl}$
$17 \mathrm{~b}$
R: $\mathrm{OH}$
$17 \mathrm{c}$
R: $\mathrm{OCH}_{3}$

Figure 23. Antimicrobial 1,4-DHPs with bulk groups at C-3 and C-5 positions

In 2011, 1,4-DHPs possessing thiosemicarbazide moieties at C-3 and C-5 were subjected to antimicrobial studies (83). It was demonstrated that these compounds were better antibacterial and antifungal agents than 3,5-diester derivatives. 18a was found to be highly active against Klebsiella pneumoniae and $\mathbf{1 8 b}$ was the most potent compound against $E$. coli according to the antimicrobial evaluations. 18a and $\mathbf{1 8 b}$ were also both excellent antifungals against Cryptococcus 
neoformans and Candida albicans, respectively (Figure 24). Kumar et al. showed that compounds with thiosemicarbazide moieties at C-3 and C-5 and, at the same time, electron donor substituents ($\mathrm{OH}$ and $\left.-\mathrm{OCH}_{3}\right)$ on the $\mathrm{C}-4$ position of the phenyl, had good inhibitory activities against gram positive and gram negative bacteria and fungi (83).<smiles>[R]c1ccc(C2C(C(=O)NNC(N)=S)=C(C)NC(C)=C2C(=O)NC(N)=S)cc1</smiles>

\begin{tabular}{lccccc} 
& \multicolumn{5}{c}{ Zone of inhibition at $\mathbf{1 0 0} \boldsymbol{\mu g} / \mathbf{m L}(\mathbf{m m})$} \\
& $\mathbf{R}$ & K. pneumoniae & E. coil & C. neoformans & C. albicans \\
18a & $\mathrm{OCH}_{3}$ & 18 & - & 24 & - \\
$\mathbf{1 8 b}$ & $\mathrm{OH}$ & - & 25 & - & 26 \\
Ciprofloxacin & 19 & 27 & - & - \\
Clotrimazole & - & - & 25 & 24
\end{tabular}

Figure 24. Structures of 1,4-DHPs possessing thiosemicarbazide moieties at C-3 and C-5

Kumar et al. also explained the antimicrobial activities of structures mimicking the thiosemicarbazide moieties at C-3 and C-5 positions of 1,4-DHP ring in another report (30). Molecule 19 was potent against $A$. niger and $C$. albicans at 100 $\mu \mathrm{g} / \mathrm{mL}(\mathrm{ZI}=17$ and $20 \mathrm{~mm}$, respectively; ZIs for Clotrimazole were 22 and $18 \mathrm{~mm}$, respectively) (84) Figure 25.<smiles>CC1=C(c2nnc(S)n2N)C(c2ccco2)C(c2nnc(S)n2N)=C(C)N1</smiles>

19

Figure 25. Chemical structure of compound 19

Solanki et al. demonstrated that the presence of bulk substituents on C-3 and C-5 made the compound more potent against bacteria and fungi (85). They also concluded that the presence of $-\mathrm{Cl}$ on the phenyl rings of $\mathrm{C}-3$ and $\mathrm{C}-5$ phenyl carboxamide moieties, along with a variation in solubility, play an important role in determining the antimicrobial activity of the compounds. For example, compound 20a possessed effective antibacterial activity against Streptococcus pyogenes (Figure 26). Akbarzadeh et al. $(79,80)$ also e concluded that compounds with a chloro group at the meta position of this ring have high antimicrobial potency (Figures 19,20).

Solanki et al. demonstrated that the presence of fluoro and nitro groups on any position of the C-3 and C-5 phenyl carboxamide moieties increases the activity, whereas any other group at para reduces the activity (20b and 20c) (85) Figure 26.<smiles>[R]c1ccc(NC(=O)C2=C(C)NC(C)=C(C(=O)Nc3ccccc3)C2c2c(C)nn(-c3ccccc3)c2Cl)cc1</smiles>

$\begin{array}{llr} & \mathbf{R} & \text { S. pyoger } \\ \mathbf{2 0 a} & m-\mathrm{Cl} & 11 \\ \mathbf{2 0 b} & m-\mathrm{NO}_{2} & 12 \\ \mathbf{2 0 c} & p-\mathrm{F} & 12 \\ \text { Chloramphenicole } & 13 \\ \text { Ciprofloxacin } & 19\end{array}$

Figure 26. Chemical structures and antibacterial activities of 20a-c against Streptococcus pyogenes

In 2013 a research group reported the antibacterial and antifungal activities of a series of C-3 and C-5 diphenyl carbohydrazide derivatives of 1,4-DHPs (86). The presence of $-\mathrm{NO}_{2}$ and $\mathrm{Cl}$ groups at the para and ortho positions of phenylhydrazine moieties were found to favor antibacterial (both gram positive and gram negative) and also antifungal activities. 21a, 21b and 21c showed half of the activity of Ciprofloxacin and more than half of the activity of Ketoconazole against $S$. aureus, E. coli, C. albicans and A. niger (Figure 27). 
<smiles>[R]c1ccc(NNC(=O)C2=C(C)NC(C)=C(C(=O)NNc3ccc([R])cc3[R])C2[R])c([R])c1</smiles>

Figure 27. Structures of C-3 and C-5 diphenyl carbohydrazide derivatives of 1,4-DHPs

Another research group synthesized several C-3 and C-5 dicarbohydrazide derivatives. Among the compounds evaluated for antibacterial activity, 22a showed good activity against Bacillus cereus and $E$. coli. The same was true for compound $\mathbf{2 2 b}$ against $S$. aureus and B. subtilis. This compound also displayed good antifungal activity against $C$. albicans (87) Figure 28.

Samaunnisa et al. reported compounds having bis pyrazolidine-3,5-dione moieties at C-3 and C-5 to be antibacterial and antifungal agents but less potent than the corresponding phenylhydrazine derivatives (88) Figure 29.

Abu-Melha explained that compounds with heterocyclic moieties at $\mathrm{C}-3$ and $\mathrm{C}-5$ positions showed better antimicrobial activities than their corresponding open chain ones. The tested compounds were more active against gram positive than against gram negative bacteria. 24a (MIC = $3.125 \mu \mathrm{g} / \mathrm{mL}$ ) was equipotent to Chloramphenicol $(\mathrm{MIC}=3.125 \mu \mathrm{g} / \mathrm{mL})$ against $B$. subtilis and eight times stronger than 24b $(\mathrm{MIC}=25 \mu \mathrm{g} / \mathrm{mL})$. The structures of these compounds are illustrated in Figure 30 (89).

As previously mentioned, the C-4 substituent has a determining effect on the antimicrobial activity. In almost all of the reported antimicrobial 1,4-dihydropyridines the C-4 substituent was a (substituted) phenyl ring. It is demonstrated that substitution on this ring is important for the antifungal activities (90). Compounds including $\mathrm{OCH}_{3}$ at para position displayed good inhibitory activity against the growth of Aspergillus fumigatus, e.g. 25a, but $\mathbf{2 5} \mathbf{b}$, with -OH instead of $\mathrm{OCH}_{3}$, had no inhibitory effect (Figure 31 ).

Compounds possessing heterocyclic systems substituted with phenyl derivatives have been associated with moderate antimicrobial effects. Prakash et al. provided a new series of 1,4-DHPs and evaluated their antibacterial and antifungal activities. The results showed that 26a (Figure 32) with $\mathrm{CH}_{3}$ substituent on the phenyl ring of $\mathrm{C}-4$ pyrazol was the best antibacterial among the studied compounds $\quad$ (MIC $=64 \mu \mathrm{g} / \mathrm{mL}$ against $S$. aureus; Ciprofloxacin: $5 \mu \mathrm{g} / \mathrm{mL}$ ). On the other hand, 26b without this group was the best antifungal derivative (PI of 51.1 and 58.8 against A.niger and A. flavus, respectively, while the corresponding values for Fluconazole were 81.1 and 77.7, respectively) (73).

In the report provided by Vijesh et al., other examples can be found of compounds including a pyrazole ring with different substituents on the C-4 moiety. Among these compounds, 27 showed excellent antibacterial activity, and was equipotent to Streptomycin, against E. coli, $S$. aureus and $P$. aeruginosa. The same compounds demonstrated poor antifungal activity (74) Figure 33.

Ahmed et al. reported the antimicrobial screening of several 1,4-DHPs against different bacteria and fungi. Compounds 28a and 28b shown in Figure 34 exhibited good inhibitory activity against $E$. coli, $S$. aureus and A. Niger, concluding that the presence of electron-releasing - $\mathrm{OH}$ and $\mathrm{OCH}_{3}$ enhances the antimicrobial activity, probably by interaction at a receptor site in the microorganism through hydrogen bonding. They offered confirmation of their conclusion by reference to the effects of the drugs such as Methicilline and Amoxycilline, which also possess $-\mathrm{OH}$ and $-\mathrm{OCH}_{3}$ in their structure (91).

$\mathrm{N}-1$ substitution of the 1,4-dihydropyridines which possess heteroaromatic moieties at C-3 and C-5 positions was reported by Rajput et al. 
<smiles>[R]C1C(C(=O)NN)=C(C)NC(C)=C1C(=O)NN</smiles>

\begin{tabular}{lcccccc} 
& & \multicolumn{8}{c}{ Zone of inhibition at $\mathbf{1 0 0} \boldsymbol{\mu g} / \mathbf{m L}(\mathbf{m m})$} & \\
& $\mathbf{R}$ & B. cereus & E. coli & S. aureus & B. subtilis & C. albicans \\
22a & $p$-Styryl & 12 & 12 & - & - & - \\
22b & $p$-chlorophenyl & - & - & 12 & 11 & 10 \\
Streptomycin & 24 & No Inhibition & 20 & No Inhibition & - \\
Miconazole & - & - & - & - & 17
\end{tabular}

Figure 28. The C-3 and C-5 dicarbohydrazide derivatives of 1,4-DHPs and their antimicrobial activity<smiles>[R]c1ccc(N2C(=O)CC(=O)N2C(=O)C2=C(C)NC(C)=C(C(=O)N3C(=O)CC(=O)N3c3ccc([R])cc3[R])C2[R])c([R])c1</smiles>

\begin{tabular}{lccccccc} 
& & \multicolumn{6}{c}{ Zone of inhibition at $1000 \mu \mathbf{g}(\mathbf{m m})$} \\
& $\mathbf{R}$ & $\mathbf{R}^{\mathbf{1}}$ & $\mathbf{R}^{\mathbf{2}}$ & B. subtilis & $\boldsymbol{E}$. coli & C.albicans & $\boldsymbol{A}$. niger \\
$\mathbf{2 3 a}$ & $\mathrm{C}_{6} \mathrm{H}_{4} \mathrm{OH}$ & $\mathrm{H}$ & $\mathrm{Cl}$ & 14 & - & - & - \\
$\mathbf{2 3 b}$ & $\mathrm{H}$ & $\mathrm{H}$ & $\mathrm{Cl}$ & - & 12 & - & - \\
$\mathbf{2 3 c}$ & $\mathrm{H}$ & $\mathrm{NO}_{2}$ & $\mathrm{NO}_{2}$ & - & - & 14 & 12 \\
Ciprofloxacin $(\mathbf{1 0}$ & $\boldsymbol{\mu} \mathbf{g} / \mathbf{m L})$ & 36 & 31 & - & - \\
Clotrimazole $(\mathbf{1 0} \boldsymbol{\mu} \mathbf{g} / \mathbf{m L})$ & & - & - & 29 & 25
\end{tabular}

Figure 29. Antibacterial and antifungal activities of 23a-c<smiles>[Y16]C1=C(C2=C(C)NC(C)=C(C3=NC(=S)NC(c4ccc(Cl)cc4)C3)C2C)C(C)=C(C(=O)/C=C/c2ccc(Cl)cc2)C(C)C(C(=O)/C=C/c2ccc(Cl)cc2)=C(C)N1</smiles>

Figure 30. Chemical structures of 24a and 24b 


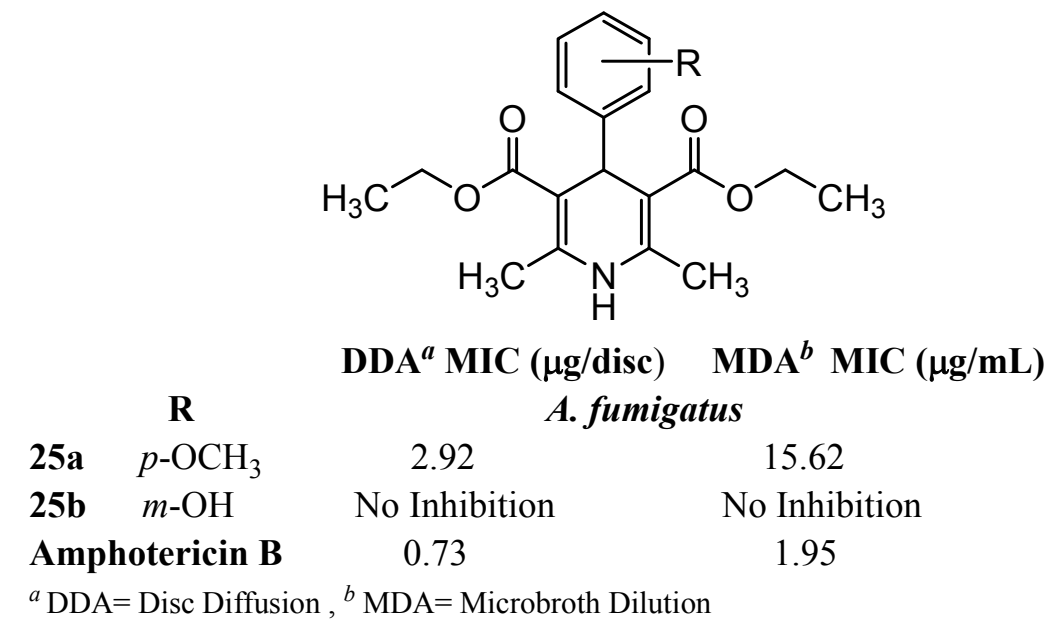

Figure 31. Chemical structures and antifungal activity of $\mathbf{2 5 a}$ and $25 \mathbf{b}$<smiles>[X]c1ccc(-c2nn(-c3ccccc3)cc2C2C(C(=O)OCC)=C(C)NC(C)=C2C(=O)OCC)cc1</smiles>

Figure 32. Structures of compounds 26a and 26b

Antimicrobial evaluation of these compounds identified moderate to good antimicrobial activity (92), and all were found to be less active against $A$. niger. Compound 29 was more potent than the standard against $C$. albicans. The structure of this compound is given in (92) Figure 35.

The same research group screened more compounds for their antimicrobial activity. They revealed that compounds $30 \mathbf{a}, 30 \mathbf{b}$ and 30c were weak against $B$. subtilis, $E$. coli and $P$. aeruginosa but, 30d (Figure 36) showed good antibacterial activity against $P$. aeruginosa, B. subtilis, E. coli and $S$. aureus. All of these compounds were found to be more potent than standard antifungal (Nystatin) against $A$. niger. The mean ZI for 30e was $19.39 \mathrm{~mm}$ and for Nyastatin $9.53 \mathrm{~mm}$, both at $100 \mu \mathrm{g} / \mathrm{mL}$ (93).
It seems that the presence of a thiazolidinone moiety favors antifungal activity, while compounds with isoxazole rings at the same positions show poor potency against $A$. niger $(92,93)$.

Mithlesh et al. reported the preparation and high antibacterial and antifungal activities of a series of 1,4-dihydropyridine derivatives. Compounds 31a and 31b, shown in Figure 37 exhibited very high antibacterial and antifungal potencies. It was concluded that the nitro group, with its lone pair of electrons, plays an important role in the antimicrobial activity by forming complexes with microbial metaloenzymes (94).

N-1 phenyl substituted 1,4-dihydropyridines which have another phenyl ring substituted on the C-4 moiety, bearing substituents on both phenyl rings have been subjected to antimicrobial evaluations. All the compounds with a chloro group substituted on the $\mathrm{N}-1$ phenyl ring were better antibacterials than antifungals. 32a inhibited $P$. vulgaris growth with a $21 \mathrm{~mm}$ zone of inhibition (Amoxicillin $=25 \mathrm{~mm})$. Compound 32b was almost as strong as amoxicillin against $E$. coli $(\mathrm{ZI}=23$ $\mathrm{mm}$, for Amoxicillin = $25 \mathrm{~mm}$ ). Replacing the para-chloro group in 32c with para- $\mathrm{OCH}_{3}$ caused a change in the antimicrobial potency in favor of antifungal activity. 32d inhibited A. Niger growth with $23 \mathrm{~mm}$ zone of inhibition, while Griseofulvin, as the standard drug, had ZI $=24 \mathrm{~mm}$ (95) Figure 38 . 
<smiles>CCOC(=O)C1=C(C)NC(C)=C(C(=O)OCC)C1c1c[nH]nc1-c1ccc(Cl)cc1</smiles>

\begin{tabular}{lcccccc} 
& & \multicolumn{2}{c}{ Zone of inhibition at $\mathbf{1} \boldsymbol{\mu g} / \mathbf{m L}(\mathbf{m m})$} \\
$\mathbf{2 7}$ & E. coli & S. aureus & P. aeruginosa & A. flavus & C. keratinophilum & C. albicans \\
Streptomycin & 17 & 15 & 16 & 2 & 3 & 4 \\
& 16 & 15 & 16 & 13 & 17 & 22
\end{tabular}

Figure 33. Chemical structures and antimicrobial activity of compound 27

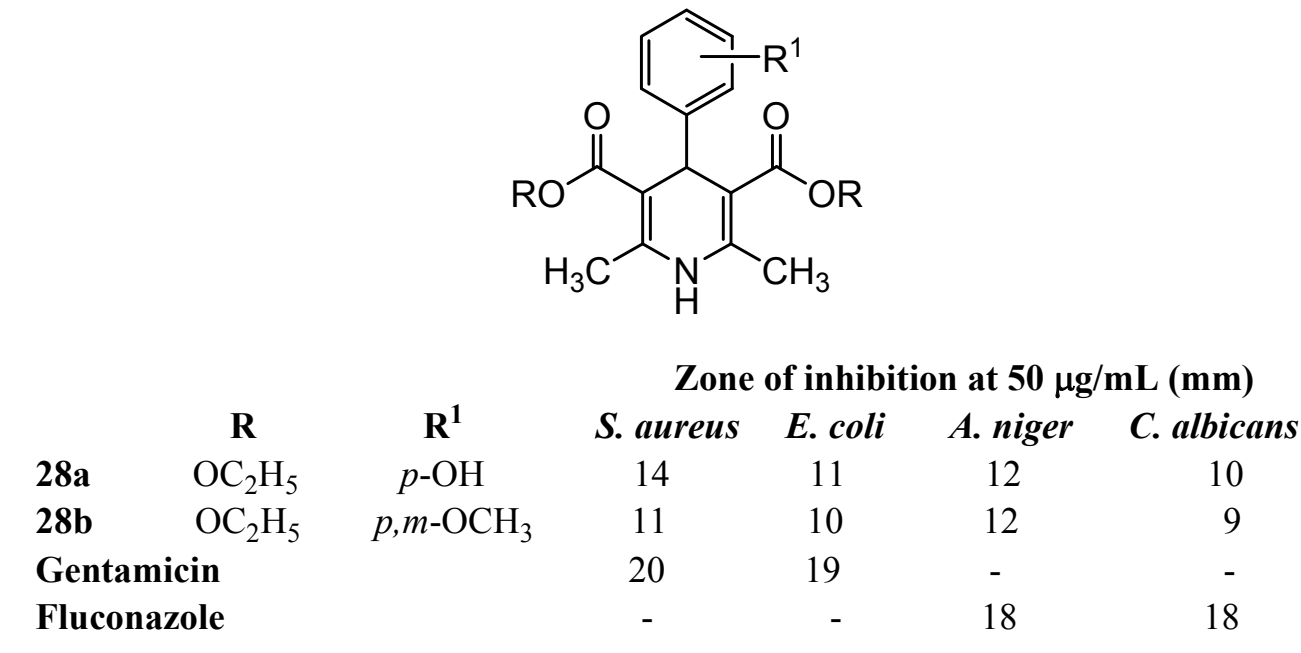

Figure 34. Chemical structures and antimicrobial activity of $\mathbf{2 8 a}$ and $\mathbf{2 8 b}$<smiles>ClC1=C(c2cc(-c3ccccc3)no2)CC(c2cc(-c3ccccc3)no2)=C(Cl)N1c1ccccc1</smiles>

Zone of inhibition at $100 \mu \mathrm{g} / \mathrm{mL}(\mathrm{mm})$

29

Nyastatin
C. albicans

9.57

9.53

Figure 35. Structure of $\mathbf{2 9}$ and its antifungal activity against $C$. albicans 


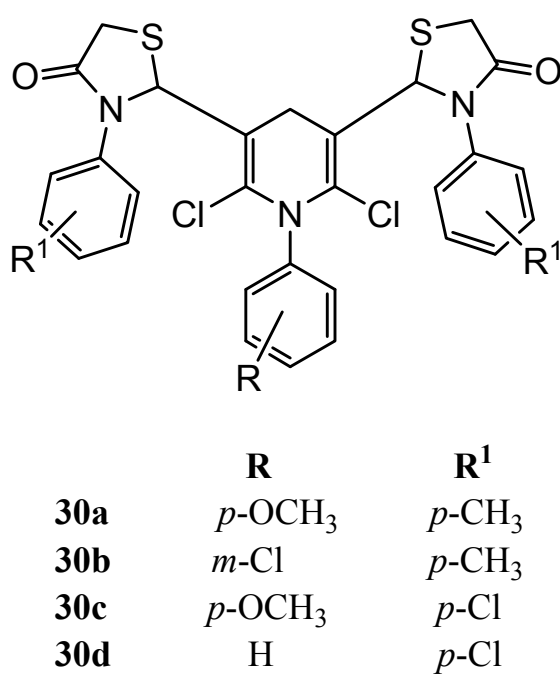

Figure 36. Chemical structures of some antimicrobial N-1 substituted 1,4-dihydropyridines

\section{ANTICANCER ACTIVITY}

One of the major clinical problems during antitumor chemotherapy is the development of multidrug-resistance (MDR) in tumor cells (96). MDR is defined as the increased efflux of a broad class of hydrophobic cytotoxic drugs mediated by one of a family of energy-dependent transporters, known as ATP-binding cassette (ABC) transporters. Several members of the ABC transporter family, such as P-glycoprotein (P-gp, also known as MDR1), can induce multidrug-resistance. Researchers have worked to develop drugs that either evade efflux or inhibit the function of efflux transporters. A large number of structurally diverse compounds have been identified as MDR inhibitors (98). These compounds in general have aromatic moieties in their structure, are highly lipophilic and possess monocationic or dicationic side chains. Most of them also have a protonated nitrogen group at physiological $\mathrm{pH}$.

Because of their affinity for P-gp, 1,4dihydropyridines have become the most extensively investigated compounds as P-gp inhibiting agents (98). It is interesting that 1,4-DHPs which lack calcium antagonistic activity or are weak calcium channel blockers possess this property (98-100). In addition, the presence of a hetaryl group at 4position of DHP was found to be effective at increasing MDR-inhibiting activity (101). The literature shows that the type of C-3, C-4 and C-5 substituents and also the lipophilicity of the molecule have important effects on the anticancer activity of 1,4-dihydropyridine compounds.

Based on QSAR/QSPKR (quantitative structure-activity/pharmacokinetics relationship) prediction models, 1,4-DHPs with potent P-gp inhibitory effects and minimal $\mathrm{Ca}^{2+}$ channel blocking activity have been reported. The results suggested $\log \mathrm{P}$ as a highly correlated parameter with P-gp inhibitory effect in Daunomycin cytotoxicity (102).

Tasaka et al. (2001) reported MDR-reversing symmetric 1,4-dihydropyridines possessing an $n$ pentyl group at the C-4 position. Based on Ford et al., compounds with one or more tertiary amino groups had a strong MDR-reversing effect and a cyclic amine was more effective than a noncyclic one (103). Compounds with these characteristics were designed for the investigation by Tasaka et al. (104). Some of the results are summarized in Figure 39. The reported resistance index was determined from the $\mathrm{IC}_{50}$ of Doxorubicine (DXR) with the test compounds $(1 \mu \mathrm{g} / \mathrm{mL})$ in $\mathrm{KB} / \mathrm{VJ} 300$ cells divided by the $\mathrm{IC}_{50}$ of DXR without test compounds in the KB cells. Antitumor activity was determined by the survival days of mice treated with Vincristine (VCR) $(0.1 \mu \mathrm{g} / \mathrm{kg}$, ip) with the test compounds (100 $\mu \mathrm{g} / \mathrm{kg}$, ip) divided by the survival days of mice treated by VCR $(0.1 \mu \mathrm{g} / \mathrm{kg}$, ip $)$ alone.

The results showed that 33a had no antitumor activity, presumably because it lacked a tertiary amino group. 33b and 33c were effective antitumor 
agents; 33b was a better MDR-reversing compound according to the resistance index values obtained. Replacement of one of the 3-pyridylpropylesters with a substituted piperazinylpropyl group provided compounds with lower resistance index values in vitro and in vivo, amongst which 33d showed the best activity. 33e indicated that the nitrogen atom at the 2-position in 2-pyridylpropylester is probably sterically hindered and therefore less effective than
3- or 4-pyridylpropylesters. Compound 33f revealed that substitution by 4-pyridylpropylester was associated with high MDR activity. Compounds such as 33b and 33e, with weak calcium antagonistic activities showed effective MDRinhibiting activities both in vitro and in vivo. In particular, 33e was expected to be the most suitable compound to overcome MDR (104).

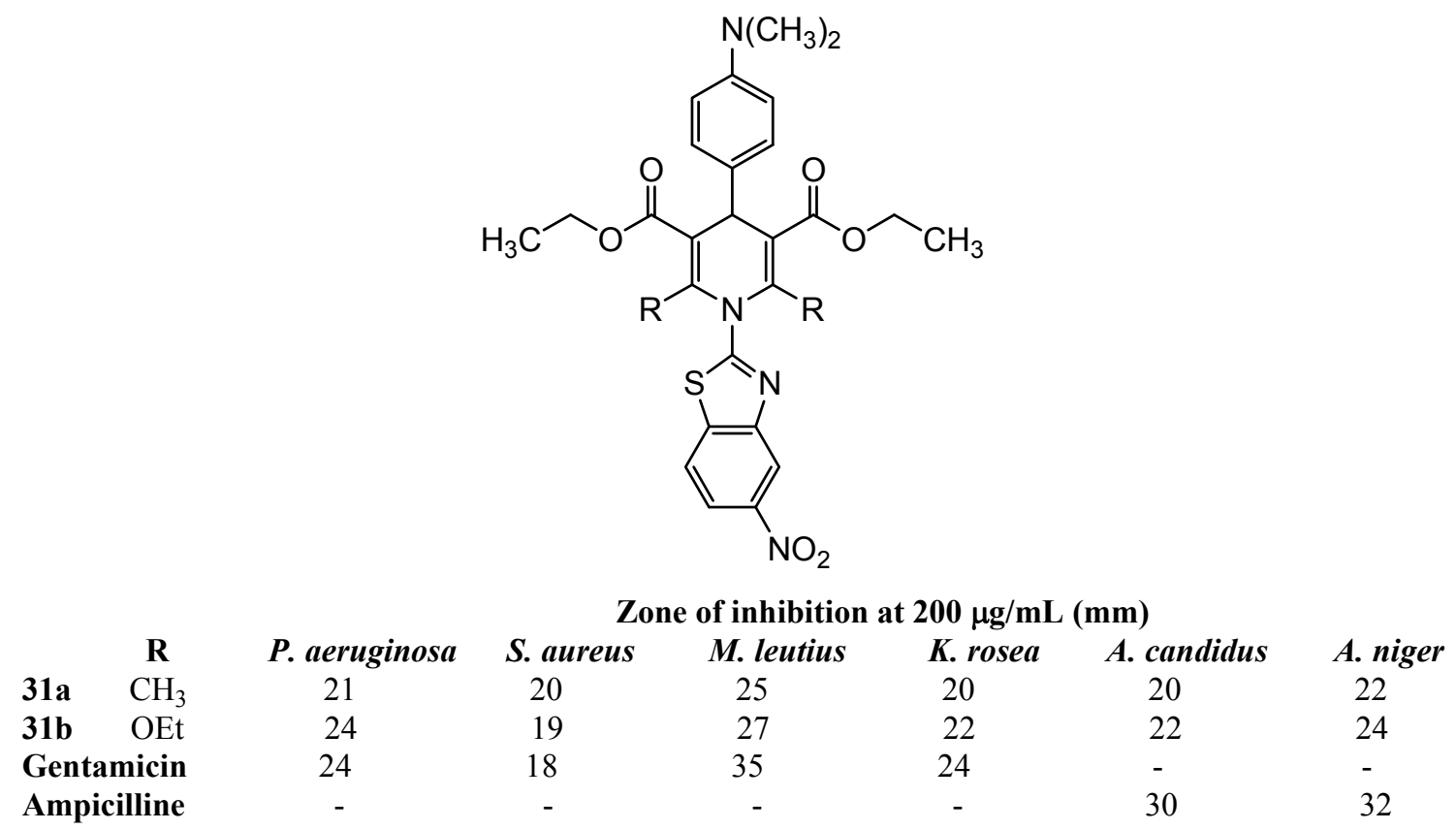

Figure 37. Antibacterial and antifungal activities of 31a and 31b<smiles>[R]OC(=O)C1=C(C)N(c2cccc([R])c2)C(C)=C(C(=O)O[R])C1c1ccc(-c2ccc(F)c(Cl)c2)o1</smiles>

\begin{tabular}{lll} 
& \multicolumn{1}{c}{$\mathbf{R}$} & $\mathbf{R}^{\mathbf{1}}$ \\
32a & $\mathrm{C}_{2} \mathrm{H}_{5}$ & $o-\mathrm{Cl}$ \\
32b & $\mathrm{CH}_{3}$ & $m-\mathrm{Cl}$ \\
32c & $\mathrm{C}_{2} \mathrm{H}_{5}$ & $p-\mathrm{Cl}$ \\
32d & $\mathrm{C}_{2} \mathrm{H}_{5}$ & $p-\mathrm{OCH}_{3}$
\end{tabular}

Figure 38. Structures of N-1 substituted 1,4-DHPs with antibacterial and antifungal activities 
<smiles>[R]OC(=O)C1=C(C)NC(C)=C(C(=O)O[R])C1CCCCC</smiles><smiles>[R]OC(=O)C1=C(C)NC(C)=C(C(=O)OCCCN2CCN(C(c3ccccc3)c3ccccc3)CC2)C1CCCCC</smiles>
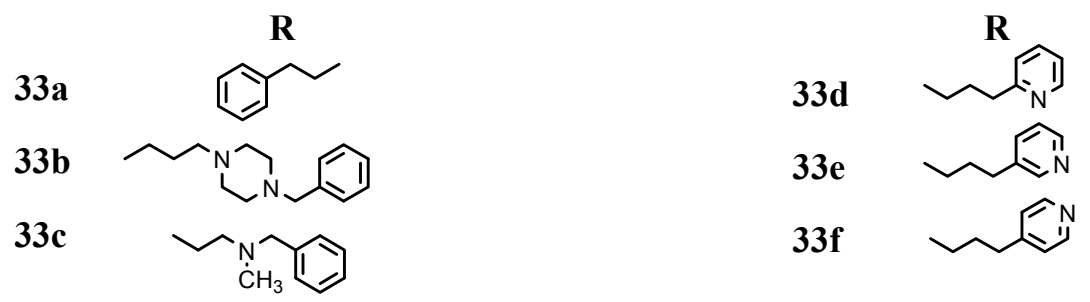

Figure 39. Chemical structures of 1,4-dihydropyridines possessing an $n$-pentyl group at the C-4 position

In another study, asymmetric compounds with a bulk group at C-3 position were synthesized and their P-glycoprotein-inhibitory activities were evaluated in human breast cancer MCF-7 cells. These compounds restored the intracellular drug accumulation by inhibiting P-glycoprotein efflux activity. For instance, compounds 34a and 34b demonstrated a 15-fold increase in Vinblastine accumulation in P-glycoprotein-overexpressed MCF-7/adr cells. Pyridine derivatives such as 35a and 35b demonstrated stronger inhibitory effects than the corresponding 1,4-dihydro analogues, 34a and 34b. Thus, the oxidation of the 1,4dihydropyridine ring to the corresponding pyridine may favor P-glycoprotein interaction (105). Results from the Daunomycin cytotoxicity assays were in agreement with those from the Vinblastine accumulation assays. The $\mathrm{IC}_{50}$ values in Figure 40 are the inhibitory concentrations of Daunomycin in the presence of $3 \mu \mathrm{M}$ of the studied 1,4dihydropyridines or Niguldipine.

In 2002, Kawase et al. investigated the MDRreversal activities of 3,5-dibenzoyl-1,4dihydropyridines against mouse lymphoma cells transfected with human MDR1 gene. They also studied the cytotoxic activity of the compounds against human oral tumor cell lines. The compounds demonstrated very variable cytotoxic activity against HSC-2 and HSG tumor cell lines. This variation was dependent on the difference in the substituents at the $\mathrm{C}-4$ position. Compounds 36a and 36b displayed the highest cytotoxic activity against HSC-2 $\left(\mathrm{IC}_{50}=7.0 \mu \mathrm{M}\right)$ and $\mathrm{HSG}\left(\mathrm{IC}_{50}=8.7\right.$ $\mu \mathrm{M})$ (Figure 41). Cytotoxicity was nearly the same as that of Doxorubicine $\left(\mathrm{IC}_{50}=4.1 \mu \mathrm{M}\right.$ and $5.3 \mu \mathrm{M}$, respectively). 36a was found to be more active than the others. It seems that $\mathrm{Cl}$ substitution at metha position on the phenyl ring leads to a higher cytotoxic and MDR-inhibiting activity than that at the ortho or para positions. However, metha-Br derivative 36c was inactive (5). Lipophilicity was one of the most important parameters affecting MDR-modulating efficiency in the structureactivity relationship studies of MDR-modulating drugs (98). The $\operatorname{LogP}$ values of molecules were calculated and found to be higher $(\operatorname{LogP}=4.26-$ 7.47) than the corresponding values of Verapamil $(\log \mathrm{P}=3.71)$ or Nifedipine $(\log \mathrm{P}=2.35)$. It was also mentioned that lipophilicity alone was not an essential parameter of direct MDR-modulating activity of this series of compounds (5).

Morshed et al. reported that compounds 36a and 36b from the above research had higher cytotoxicity against the tumor cell lines (HSC-2, HSC-3, HSG, HL-60) than normal cells (HGF, HPC, HPLF), yielding a tumor specific (TS) cytotoxicity value of $>33$ and $>53$, respectively. Western blot analysis showed that 36a and 36b transiently increased the expression of both the antiapoptotic protein (Bcl-2) and pro-apoptotic proteins 
(Bax, Bad) at lower concentrations $(2.5-40 \mu \mathrm{M})$, and reduced their expression at higher concentrations in HL-60 cells (6) Figure 41. They concluded that 3,5-dibenzoyl-1,4-dihydropyridines,

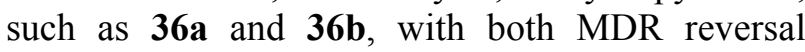
activity (5) and tumor-specific cytotoxicity, may be possible antitumor candidates (6).

Another research group explained the antiproliferative effects of 1,4-dihydropyridine derivatives in comparison with those of Verapamil (VP) and Doxorubicin. The human breast cancer T47D cell line and its MDR1 over-expressed and moderately resistant cells (RS) were used in this research. They also examined the effects of these compounds on cytotoxicity of Doxorubicin in these two cell types. The cytotoxicity of the molecules was similar to that of Verapamil, and significantly less than that of Doxorubicin. Among these compounds, 37a and 37b showed promise as potential new MDR1 reversal agents (106) Figure 42.

Thiosemicarbazide derivatives of 1,4dihydropyridines had significant antitumor activity (107). Kumar et al. explained the anticancer activity of a new series of 1,4-dihydropyridine derivatives against HepG2 and Hela cancer cell lines. Compound 38a was more active than the other compounds against HepG2 and MCF-7. Likewise, 38b was more active than the other molecules against Hela cancer cells (108) Figure 43.<smiles>[R]c1ccc(C2C(C(=O)OCCCN3CCC(c4ccccc4)(c4ccccc4)CC3)=C(C)NC(C)=C2C(=O)OCCCN2CCC(c3ccccc3)(c3ccccc3)CC2)cc1</smiles>

Figure 40. Structures and anticancer activity of $\mathbf{3 4 a}, \mathbf{3 4 b}, \mathbf{3 5 a}$ and $35 \mathbf{b}$ in combination with Daunomycin<smiles>[R]C1=C(C(=O)Oc2ccccc2)C(c2ccccc2)C(C(=O)Oc2ccccc2)=C(C)N1</smiles>

Figure 41. Anticancer 3,5-dibenzoyl-1,4-dihydropyridines 
<smiles>[R]C(=O)C1=C(C)NC(C)=C(C([R])=O)C1c1csc([R])n1</smiles>

\begin{tabular}{llcll} 
& & & \multicolumn{2}{c}{$\mathbf{I C}_{\mathbf{5 0}}(\boldsymbol{\mu M})$} \\
\multicolumn{1}{c}{$\mathbf{R}^{\mathbf{1}}$} & $\mathbf{R}^{\mathbf{2}}$ & $\mathbf{T 4 7 D}$ & $\mathbf{R S}$ \\
37a & o-methyl & phenyl & 113 & 141 \\
37b & o-chlorophenyl & methyl & 121 & 126 \\
DXR & & & 0.399 & 0.545 \\
VP & & 123 & 108 \\
36a+DXR & & 0.296 & 0.327 \\
36b+DXR & & 0.267 & 0.288 \\
VP+DXR & & 0.267 & 0.316
\end{tabular}

Figure 42. The antiproliferative effects of $\mathbf{3 7 a}$ and $\mathbf{3 7} \mathbf{b}$ in combination with Verapamil and Doxorubicin<smiles>[X]C(=[X])NNC(=O)C1=C(C)NC(C)=C(C(=O)N/N=C(\[X])N)C1c1ccc(O)c(OC)c1</smiles>

\begin{tabular}{|c|c|c|c|c|}
\hline \multirow{2}{*}{\multicolumn{2}{|c|}{$\mathbf{X}$}} & \multicolumn{3}{|c|}{$\mathbf{G I}_{\mathbf{5 0}}{ }^{a}(\boldsymbol{\mu M})$} \\
\hline & & HepG2 & MCF-7 & Hela \\
\hline $38 \mathbf{a}$ & $\mathrm{O}$ & 31.2 & 32.3 & - \\
\hline $38 b$ & $\mathrm{~S}$ & - & - & 31.1 \\
\hline Dox & rubicin & 0.01 & 0.02 & 0.05 \\
\hline
\end{tabular}

Figure 43. (Thio)semicarbazide derivatives of 1,4-DHPs and their antitumor activity

The structural requirements of 1,4-dihydropyridines for MDR reversal were also investigated using the molecular docking technique on multidrug resistance protein 1 (MRP1). Sirisha et al. subjected a series of 1,4-DHP derivatives to MDR inhibiting activity assessment and molecular docking studies. It was observed that only two test compounds, 39a and 39b, induced inhibition of MRP1 basal ATPase activity at concentrations above $10 \mu \mathrm{M}$. Compound 39b was shown to be relatively more potent than 39a according to the docking results. The structures of these compounds and the experimental and computational results are provided in Figure 44. The $\mathrm{IC}_{50}$ values corresponding to the inhibitory concentration of the compounds against the MRP1 and $\mathrm{Ki}$ values are the in silico calculated inhibitory concentrations. A correlation between docking scores and experimental binding data suggested that 
this technique might be useful for developing a pharmacophore model to help interpret the affinities observed and to design new MRP1 antagonists (109).<smiles>[X]c1ccccc1NC(=O)C1=C(C)NC(C)=C(C(=O)Nc2ccccc2)C1Br</smiles>

\begin{tabular}{|c|c|c|c|c|}
\hline \multirow[b]{3}{*}{ 39a } & \multirow[b]{2}{*}{$\mathbf{X}$} & \multirow{3}{*}{$\begin{array}{c}\mathbf{A r} \\
o \text {-furyl }\end{array}$} & $\mathrm{IC}_{50}($ & $\mathbf{K}_{\mathrm{i}}^{a}(\mu \mathbf{M})$ \\
\hline & & & \multicolumn{2}{|c|}{ MRP1 } \\
\hline & $\mathrm{CH}$ & & 20 & 0.95 \\
\hline 39b & $\mathrm{N}$ & $o$-pyrrolyl & 14 & 0.66 \\
\hline \multicolumn{3}{|c|}{ Benzbromarone } & 4 & 0.19 \\
\hline
\end{tabular}

Figure 44. Experimental and computational values for the inhibition of MRP1 by 39a and 39b

Inhibition of the MDR reversal activity of 1,4dihydropyridine derivatives using a multidrugresistant human colon cancer cell line expressing MDR1/LRP and a human $m d r l$ gene-transfected mouse lymphoma cells was reported by Engi et al. The tumor-specific cytotoxicity of these compounds against human tumor and normal cell lines was also investigated. Compound 40a displayed a marked inhibition of the MDR of mouse lymphoma cells. 40b had a very strong tumor-specific cytotoxic action, with TS $\left(\mathrm{CC}_{50}\right.$ normal/ $\mathrm{CC}_{50}$ tumor) of 5.9 $\mu \mathrm{M}$ (TS of Doxorubicin was $>14.6 \mu \mathrm{M}$ ). The dihydropyridine derivatives were more cytotoxic against tumor cell lines as compared with normal cell lines (110) Figure 45.<smiles>[R]OOC(=O)OCC</smiles>

Figure 45. Chemical structures of $40 \mathrm{a}$ and $40 \mathrm{~b}$

Evaluation of the antiproliferative effects of a series of new imidazole-substituted indeno[1,2b] quinoline-9,11-dione derivatives on HeLa, LS180, MCF-7 and Jurkat human cancer cell lines was reported in 2013. These molecules showed more activity against the Jurkat cell line than the LS180, MCF-7 and Hela cell lines. It was concluded that compounds bearing an imidazole-2yl moiety at the $\mathrm{C}-11$ position of DHP have stronger antiproliferative activity than Cisplatin against the Jurkat cell line. Also the presence of electron-withdrawing groups on the imidazole ring increased the antiproliferative potential of the molecules (111) Figure 46.

\section{1,2,3,4-TETRAHYDROPYRIMIDINES ANTITUBERCULAR ACTIVITY}

As mentioned above, 1,2,3,4-tetrahydropyrimidines share many biological properties with 1,4dihydrpyridines. 1,2,3,4-THPMs and some full aromatic pyrimidine derivatives have also shown antitubercular activities. Structural features affecting the antitubercular potency of these compounds are the nature of C-2, C-4 and C-5 substituents and also the lipophilicity of the compound. Most of the reported antitubercular 1,2,3,4-THPM derivatives have one of the general structures shown in Figure 47. 


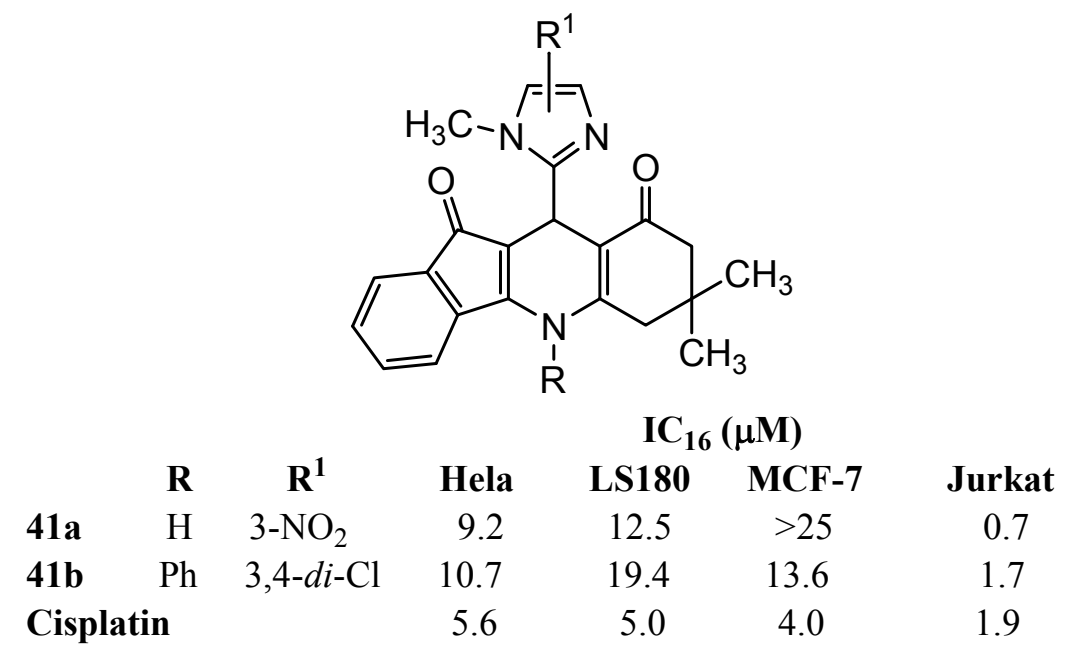

Figure 46. Fused-ring anticancer 1,4-DHPs<smiles>[X]C1NC(C)=C(C(=O)N[Ga])C(Br)N1</smiles><smiles>[R]C(=O)C1=C(C)NC([X])NC1[Al]</smiles>

Figure 47. Structural categories of antitubercular 1,2,3,4-THPMs

Carbonyl and thiocarbonyl groups are the most common types of functional groups in the C-2 position of 1,2,3,4-THPM derivatives. As with 1,4DHPs, substituted phenyl and heteroaromatic rings have been studied as the C-4 substituents of both 1,2,3,4-THPMs and pyrimidine derivatives. Both the 5-phenylcarboxamide and 5-alkylcarboxylate esters of the 1,2,3,4-THPM scaffold have been seen to possess antitubercular properties $(13,112-116)$.

Based on the structures of the active derivatives, lipophilicity seems to be an important physicochemical property affecting the compound's potency. However, the lipophilicity of the substituents at any position of the molecule cannot be considered the only determining factor. Regarding the C-2 substituent, no specific relationship between the potency and the type of this substituent (carbonyl or thiocarbonyl) can be found. For example, compound 42a (MIC $=16$ $\mu \mathrm{g} / \mathrm{mL}$ ) was more potent than $\mathbf{4 2} \mathbf{b}$, with an MIC of $32 \mu \mathrm{g} / \mathrm{mL}$, but $42 \mathrm{c}$ (MIC $=32 \mu \mathrm{g} / \mathrm{mL}$ ) was as potent as 42d, while $42 \mathrm{e}(\mathrm{MIC}=0.25 \mu \mathrm{g} / \mathrm{mL})$ was weaker than $\mathbf{4 2 f}(\mathrm{MIC}=0.125 \mu \mathrm{g} / \mathrm{mL})$ as reported by Yadlapalli et al. The minimum inhibitory concentration of Isoniazid was determined to be
$0.03 \mu \mathrm{g} / \mathrm{mL}$ by the same author (13) Figure 48 . The same is true for the report of Trivedi et al. (114), who also changed the thiocarbonyl to a thiomethyl moiety, observing a decrease in the potency of most of the compounds, which did not agree with the increase in their lipophilicity values.

The C-4 derivatives are lipophilic aromatic or heteroaromatic moieties and it seems that the amount of this physicochemical property affects potency. This can be exemplified by the two THPM derivatives illustrated in Figure 49. Compound 43a with $\log \mathrm{P}=4.77$ was more potent than $43 \mathrm{~b}(\log \mathrm{P}$ $=4.27$ ) (115).

The position of the substitution on the C-4 phenyl moiety was discussed by Virsodia et al. (115). Substituted N-aryl-6-methyl-2-oxo-4-phenyl1,2,3,4-tetrahydro-pyrimidine-5-carboxamides which had antitubercular activity were subjected to a 3D-QSAR study by this group, who concluded, from the CoMFA electrostatic contours, that electropositive groups are favored at the ortho', meta and para positions of the 4-phenyl ring. The substitution pattern of these compounds is illustrated in Figure 50. 


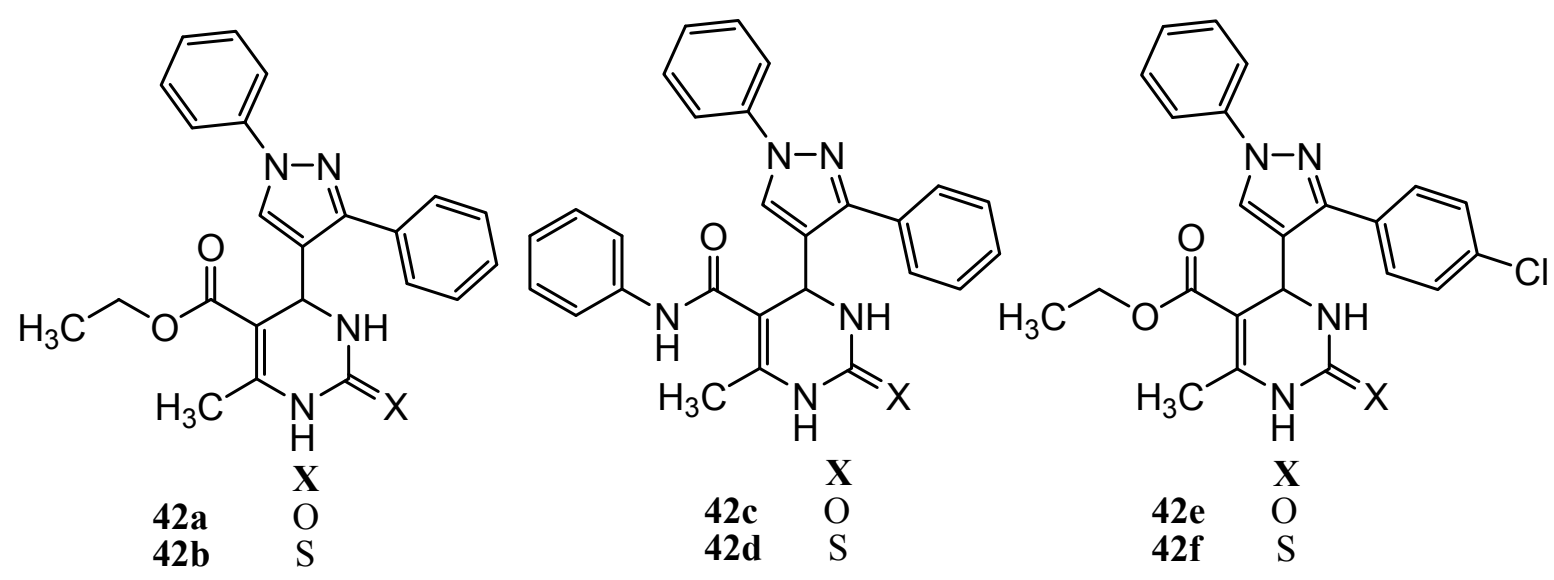

Figure 48. Molecular structures of 42a-f

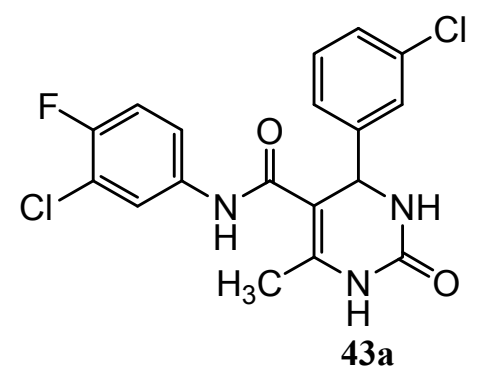<smiles>CC1=C(C(=O)Nc2ccccc2F)C(c2cccc([N+](=O)[O-])c2)NC(=O)N1</smiles>

$\begin{array}{lcc} & \text { PI at }> & \mathbf{6 . 2 5} \boldsymbol{\mu g} / \mathbf{m L} \\ \mathbf{4 3 a} & 48 \\ \mathbf{4 3 b} & 24 \\ \text { Rifampicin } & 99\end{array}$

Figure 49. Chemical structures and PIs of antitubercular 1,2,3,4-THPMs<smiles>CC1=C(C(=O)NCCl)C(c2ccccc2)NC(=O)N1</smiles>

Figure 50. The substitution pattern of substituted N-aryl6-methyl-2-oxo-4-phenyl-1,2,3,4-tetrahydro pyrimidine5 -carboxamides

They also indicated that electronegative groups at the meta position of this ring increase the activity. Using the CoMSIA electrostatic contours, they confirmed that electropositive groups are favored at the para and ortho positions of the 4- phenyl ring. According to the CoMFA steric fields and steric CoMSIA contours reported by this group, bulky substituents are not favored at the para position of the 4-phenyl ring. Mapping the desired and undesired hydrophobic regions on this ring, they demonstrated that hydrophobic groups at the meta' and para positions decrease the activity. Hydrogen bonding with an $\mathrm{H}$-bond donor at the meta' and para positions of the 4-phenyl ring was also confirmed to be favorable (115).

Between the 5-phenylcarboxamides and 5alkylcarboxylate esters of the 1,2,3,4-THPMs scaffold, the latter derivatives proved to have superior antitubercular properties. For example, $\mathbf{4 2 f}$ was 256 and $\mathbf{4 2 e}$ was 128 times more potent than 42c and 42d, respectively (13) Figure 48. A smaller difference in the magnitude of the activity was mentioned in the report of Zalavadiya et al. (116). 
5-Alkylcarboxylate ester 44a exhibited a growth inhibition percentage of 65 , which was stronger than that for the corresponding phenylcarboxamide derivative, $\mathbf{4 4 b}$, with a growth inhibition percentage of 3.0, while Rifampicin, as the standard drug, showed a growth inhibition percentage of 98 , all at $6.25 \mu \mathrm{g} / \mathrm{mL}$ (Figure 51). The results of other research articles confirm the higher potency of the ester derivatives (114).<smiles>CCOC(=O)C1=C(C)N(c2ccc(OC)cc2)C(=O)NC1c1ccccc1</smiles><smiles>COc1ccc(N2C(=O)NC(c3ccccc3)C(C(=O)Nc3ccc(C)cc3)=C2C)cc1</smiles>

44b
Figure 51. Chemical structures of $44 a$ and $44 b$

The 3D-QSAR study by Virsodia et al. also clarified some structural features of the 5phenylcarboxamide moiety and its influence on potency. According to the CoMFA electrostatic contours obtained in this study, electropositive groups are favored at the meta position of the $5 \mathrm{~N}$ phenyl ring. The CoMSIA electrostatic contours favored the electronegative groups at the para position of this ring. The CoMFA steric fields confirmed meta position on the $5 \mathrm{~N}$-phenyl moiety as the favored position for bulky substituents. Using hydrophobic contours of CoMSIA, Virsodia et al. indicated that hydrophobic groups positioned at meta' decrease the activity, but small hydrophobic groups are accepted at the meta position of the $5 \mathrm{~N}$ phenyl ring (115). This latter observation can be better understood by comparing $45 \mathbf{a}$ and $\mathbf{4 5 b}$. As can be seen, the small hydrophobic methyl group is not tolerated at meta' position in $\mathbf{4 5 a}$, but the same group in the meta position of the $5 N$-phenyl ring lends higher activity to the compound (Figure 52). $\mathrm{H}$-bond acceptor groups were disfavored in the ortho and meta positions of the ring.

Full aromatic analogues of Biginelli pyrimidines have also shown antitubercular activities, but weaker compared with the 1,2,3,4THPMs (113). 46a and 46b shown in Figure 53 are two examples of such weak antitubercular compounds.

N-1 substitution on both 5-phenylcarboxamide and 5-alkylcarboxylate esters of 1,2,3,4-THPMs led to weak to moderate compounds (116) Figure 54.

Ring fusion to the $\mathrm{C} 5=\mathrm{C} 6$ bond of the tetrahydropyrimidine moiety (reported by Trivedi et al.) led to some pyrazolo[3,4- $d]$ pyrimidines being regarded as promising antiTB compounds (114) Figure 55.

\section{ANTIMICROBIAL ACTIVITY}

Microbial infections comprise a group of diseases that have been common since the beginning of humankind. Even with the enormous achievements that have been made in the field of antimicrobial medications, there is still no perfect solution to many of the deadly diseases caused by bacteria (117).<smiles>CC1=C(C(=O)Nc2cccc(C)c2C)C(c2cccc(Oc3ccccc3)c2)NC(=O)NC1C(=O)Nc1ccccc1C</smiles>

Figure 52. Molecular structures of 45a and 45b 
<smiles>CCOC(=O)c1c(C)nc(NCCCO)nc1-c1ccccc1</smiles>

$46 a$<smiles>CCCCNc1nc(C)c(C(=O)OCC)c(-c2ccccc2)n1</smiles>

46b
$46 a$
$\operatorname{MIC}(\mu \mathrm{M})$
Moxifloxacin
Isoniazid
117.7
0.47
0.12

Figure 53. Full aromatic analogues of Biginelli pyrimidines and their antitubercular activity<smiles>CCOC(=O)C1=C(C)N(c2ccc(F)c(Cl)c2)C(=O)NC1c1ccc(F)cc1</smiles>

$47 a$<smiles>CC1=C(C(=O)Nc2ccc(C)cc2)C(c2ccc(O)cc2)NC(=O)N1c1ccc(F)c(Cl)c1</smiles>

47b

\section{7a $\quad 74$ \\ 47b $\quad 46$ \\ Rifampicin 98}

Figure 54. Antitubercular activity of N-1 substitututed 5-phenylcarboxamide and 5-alkylcarboxylate esters of 1,2,3,4THPMs

Several reports of antimicrobial activities of substituted 2 - oxo / thioxo - $1,2,3,4$ tetrahydropyrimidines have been published in the recent years (118-142). For example, Sawant et al. described the antimicrobial activity of some THPM derivatives in 2008. They screened them against the gram-positive bacteria, $S$. aureus, and observed that two of the compounds, 49a and $49 \mathbf{b}$, were more effective than others. The structures of these compounds are illustrated in Figure 56. The same research group also investigated the results using the QSAR approach and observed a good correlation between the structural features and biological activity. They concluded that molecules with a less positive partial charge and a negative polar Van der Waals surface area make a higher contribution rather than the ratio of Van der Waals surface area to molar refractivity (119). 


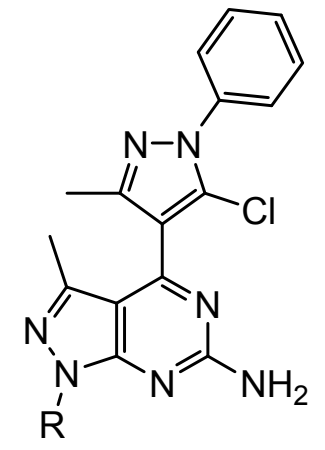

$\begin{array}{lcc} & \mathbf{R} & \text { MIC }(\boldsymbol{\mu g} / \mathrm{m} \\ \mathbf{4 8 a} & o \text {-chlorophenyl } & 1.20 \\ \mathbf{4 8 b} & p \text {-methylphenyl } & 1.20 \\ \text { Isoniazid } & & 0.20\end{array}$

Figure 55. Fused ring 1,2,3,4-THPMs and their antitubercular activity

Another series of THPM derivatives with a group substituted at N-3 providing higher Van der Waals surface area, as compounds 49a and 49b, and different groups at C-2, C-4 and C-5 positions, were screened against gram negative (E. coli and Salmonella typhi) and gram positive ( $S$. aureus and $B$. subtilis) microorganisms. Compound 50a showed good activities against S.aureus, B. subtilis, E. coli and S. typhi (MICs $=3,1,1$ and $2 \mu \mathrm{g} / \mathrm{mL}$, respectively). Chloramphenicol was used as one of the standards in this study. The corresponding MIC values for this drug were 5, 7, 6 and $7 \mu \mathrm{g} / \mathrm{mL}$. Compound 50b was also a good inhibitor of $S$. typhi growth, with an MIC $=3 \mu \mathrm{g} / \mathrm{mL}$. It was concluded that compounds which had $\mathrm{OCH}_{3}$ and/or $\mathrm{Cl}$ substitution at any position of the $\mathrm{C}-4$ phenyl group showed antimicrobial activities at lower concentrations (117) Figure 57.<smiles>[R]OC1NC(C)=C(C(=O)OCC)C(c2ccc([R])cc2)N1CC(=O)c1ccc([R])cc1</smiles>

Figure 57. Chemical structures of $\mathbf{5 0 a}$ and $\mathbf{5 0 b}$
A substituted benzoyl methyl thio group located on the $\mathrm{C}-2$ position of the THPM ring seemed to be effective in the antimicrobial activity, as effective as a moiety located on N-3 position. Hussein et al. revealed that the most active compounds of this series contained an electron-withdrawing group $\left(\mathrm{R}^{1}\right.$ $=\mathrm{Cl}, \mathrm{Br} ; \mathrm{R}^{2}=\mathrm{Br}, \mathrm{Cl}$ or $\mathrm{NO}_{2}$ ) in their structures, while the least active ones contained an electrondonating group $\left(\mathrm{R}^{1}=\mathrm{H}, \mathrm{CH}_{3} ; \mathrm{R}^{2}=\mathrm{OCH}_{3}, \mathrm{CH}_{3}\right)$. 51a was effective against $S$. aureus, E. coli and $P$. aeruginosa, while 51b (Figure 58) had antimicrobial activity against $B$. cereus, $E$. coli and $P$. aeruginosa (120).

An investigation into compounds with bulk moieties at C-4, or C-5 or a heterocyclic ring fused to the 1,2,3,4-THPM ring (Figure 59) revealed variable antimicrobial activities ranging from zero to moderate (121).

Tetrahydropyrimidines possessing bulkier groups at C-4 position were also subjected to antimicrobial assessments. Different examples of these structures will be discussed below.

Nagawade et al. described the antibacterial activity of a series of THPMs with substituted biphenyl ring against both gram positive and gram negative strains. Most of the compounds (e.g. compound 55) displayed moderate activity against the studied strains, while all the tested compounds were inactive (MIC $>32 \mu \mathrm{g} / \mathrm{mL}$ ) against $P$. aeruginosa and Enterococcus faecium, unlike the standards (Ciprofloxacin, Sparfloxacin, and Trovafloxacin) (122) Figure 60. 
<smiles>COc1ccc(C2C(C(C)=O)=C(C)NC(=O)N2C(=O)c2ccccc2)cc1</smiles>

$49 \mathrm{a}$<smiles>COC(=O)C1=C(C)NC(=S)N(C(=O)c2ccccc2)C1c1ccccc1</smiles>

49b

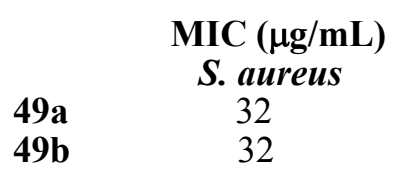

Figure 56. Chemical structures of 49a and $49 \mathrm{~b}$ and their antibacterial activity against $S$. aureus<smiles>[R]c1ccc(C(=O)CSC2=NC(c3ccc([R])cc3)C(C(=O)OCC)=C(C)N2)cc1</smiles>

\begin{tabular}{lcccccc} 
& & & \multicolumn{4}{c}{ Zone of inhibition at $\mathbf{1 0 0} \boldsymbol{\mu m o l} / \mathbf{m L}(\mathbf{m m})$} \\
& $\mathbf{R}^{\mathbf{1}}$ & $\mathbf{R}^{\mathbf{2}}$ & S. aureus & E. coli & P. aeruginosa & B. cereus \\
51a & $\mathrm{Cl}$ & $\mathrm{Br}$ & 23 & 22 & 21 & - \\
$\mathbf{5 1 b}$ & $\mathrm{Br}$ & $\mathrm{NO}_{2}$ & - & 21 & 20 & 25 \\
Chloramphenicol & & 27 & 30 & 24 & 32
\end{tabular}

Figure 58. Chemical structures and zones of inhibition at $100 \mu \mathrm{mol} / \mathrm{mL}(\mathrm{mm})$ for $\mathbf{5 1 a}$ and $\mathbf{5 1 b}$

The replacement of one of the C-4 position phenyl rings by tetrahydropyran or tetrahydropyrrolidine led to compounds with high antimicrobial activity. For example, 56a and 56b had significant activity against the selected bacteria and fungi, with zones of inhibition almost comparable to those of the standard drugs (Figure 61). It is interesting that the substituted 4-diethylaminophenyl compounds (56c and 56d) were also as potent as their closed-ring analogues 56a and 56b (123).

1,2,3,4-tetrahydropyrimidin-2(1H)-ones having a substituted urea on the $\mathrm{C}-4$ phenyl group have been evaluated for antibacterial and antifungal activities against various gram positive and gram negative bacteria as well as fungal strains. These compounds were similar to the molecules studied by Nagawade et al. (122) but differed in their C-4 substituent. The antibacterial activity data suggested that the presence of lipophilic moieties or $\mathrm{H}$-bond acceptors such as $\mathrm{F}, \mathrm{Cl}, \mathrm{CF}_{3}, \mathrm{OCF}_{3}$ and $\mathrm{OCH}_{3}$ at ortho position of the C-4 substituent favors high antibacterial activity (Figure 62). 
<smiles>CC1=C(C(=O)/C=C/c2ccc(C)o2)C(c2occc2C)NC(=O)N1</smiles><smiles>COc1ccc(C2NC(=O)NC3(C)NN=C(C)C23)cc1</smiles>

53<smiles>CCOC(=O)C1=C(C)NC(=O)NC1c1ccc(O)c(CNCCCCCN)c1</smiles>

54

\begin{tabular}{lcccccc} 
& \multicolumn{7}{c}{ Zone of inhibition at $\mathbf{1 m g} / \mathbf{m L} \mathbf{( m m})$} \\
$\mathbf{5 2}$ & C. albicans & B. subtilis & B. cereus & E. coli & P. aeruginose & S. aureus \\
$\mathbf{5 3}$ & 14 & 12 & - & - & - & - \\
$\mathbf{5 4}$ & 15 & 8 & 8 & 3 & - & 3 \\
Ref. & 15 & 2 & 9 & - & - & - \\
& 44 & 40 & 30 & 20 & 35 & 50
\end{tabular}

Figure 59. Bulk moieties at C-4, or C-5 or a heterocyclic ring fused to the 1,2,3,4-THPM and the corresponding antimicrobial activities<smiles>CCOC(=O)C1=C(C)NC(=S)NC1c1ccc(-c2cccc(C(=O)OCC)c2)cc1</smiles>

$\begin{array}{lccccc} & \text { S. aureus } & \text { E. coli } & \text { S. epidermidis } & \text { Klebsiella sp. } & \text { E. faecalis } \\ \text { 55 } & 8 & 8 & 8 & 8 & 8 \\ \text { Ciprofloxacin } & 1 & 0.007 & 1 & 0.01 & 2 \\ \text { Sparfloxacin } & 1 & 0.007 & 1 & 0.01 & 1 \\ \text { Trovafloxacin } & 0.5 & 0.002 & 0.5 & 0.025 & 1\end{array}$

Figure 60. Chemical structure and antibacterial activity of compound 55

Compounds 57a and 57b, both with $\mathrm{MIC}=10$ $\mu \mathrm{g} / \mathrm{mL}$ against $S$. aureus, and E. coli are good examples. Ciprofloxacin, which was used as the standard, had an MIC of 25 and $15 \mu \mathrm{g} / \mathrm{mL}$ against the same bacteria, respectively). But substitution at meta position or disubstitution at meta and para positions of the C-4 substituent led to moderate (or even no) activity with respect to the standard drug against the test strains. Compound 57c had no activity against $E$. coli up to $200 \mu \mathrm{g} / \mathrm{mL}$ and was a moderate antibacterial against $S$. aureus $(\mathrm{MIC}=90$ $\mu \mathrm{g} / \mathrm{mL})$. The presence of nonpolar lipophilic groups such as isopropyl or $n$-butyl at the C-4 terminal phenyl ring had no major effect on the activity (e.g. 57d with $\mathrm{MIC}=85,55$ and $95 \mu \mathrm{g} / \mathrm{mL}$ against $S$. aureus, E. coli and Salmonella typhimurium, 
respectively). The structure-activity relationships (SAR) of the molecules for antibacterial activity strongly correlated with their SAR for antifungal activity. For instance, MIC values of $\mu \mathrm{g} / \mathrm{mL}$ against $C$. albicans, $A$. niger and A. flavus were observed for 57a. In the case of Miconazole, which was used as reference drug, the MICs were 25, 20 and 20 $\mu \mathrm{g} / \mathrm{mL}$ against $C$. albicans, A. niger and A. flavus, respectively (124).

Other compounds with bulk groups at C-4 position of the THPM ring containing a rotatable bond were reported by Balaji et al. Among the tested compounds, $\mathbf{5 8}$ was the most active against $S$. aureus, B. cereus, E.coli, and P.aeruginosa (125)
THPMs containing a naphthalene ring as the C4 substituent have also been investigated for their antimicrobial properties. According to a report by Borse et al., such compounds are not strong antimicrobials. The best reported compound, 59, shown in Figure 64, had an $\mathrm{MIC}=250 \mu \mathrm{g} / \mathrm{mL}$ against four representative pathogens: E. coli, $P$. neumoniae, A. niger and C. albicans. Streptomycin was the standard drug used in the antibacterial assays, with $\mathrm{MIC}=125 \mu \mathrm{g} / \mathrm{mL}$, while Fluconazole was the standard antifungal agent $(\mathrm{MIC}=125 \mu \mathrm{g} / \mathrm{mL})(126)$.

Figure 63.<smiles>[R]OC(=O)C1=C(C)NC(=O)NC1c1ccc(N2CCCC2)cc1</smiles>

Zone of inhibition at $100 \mathrm{ppm}(\%)$

$\begin{array}{llcccc} & \mathbf{R} & \text { S. aureus } & \text { E. coli } & \text { A. niger } & \text { H. oryzae } \\ \text { 56a } & \mathrm{C}_{2} \mathrm{H}_{5} & 23 & 23 & 21 & 20 \\ \text { 56b } & \mathrm{CH}_{3} & 23 & 23 & 18 & 19 \\ \text { Penicillin } & & 20 & 20 & - & - \\ \text { Griseofulvin } & & - & - & 20 & 20\end{array}$<smiles>[R]OC(=O)C1=C(C)NC(=O)NC1c1ccc(N(CC)CC)cc1O</smiles>

Zone of inhibition at $100 \mathrm{ppm}(\%)$

$\begin{array}{lcccccc}\text { 56c } & \mathrm{C}_{2} \mathrm{H}_{5} & \mathrm{~S} & 23 & 22 & 19 & 15 \\ \mathbf{5 6 d} & \mathrm{CH}_{3} & \mathrm{NH} & 21 & 21 & 20 & 19 \\ \text { Penicillin } & & & 20 & 20 & - & - \\ \text { Griseofulvin } & & & - & - & 20 & 20\end{array}$

Figure 61. Chemical structures and antimicrobial activity of 56a-d 


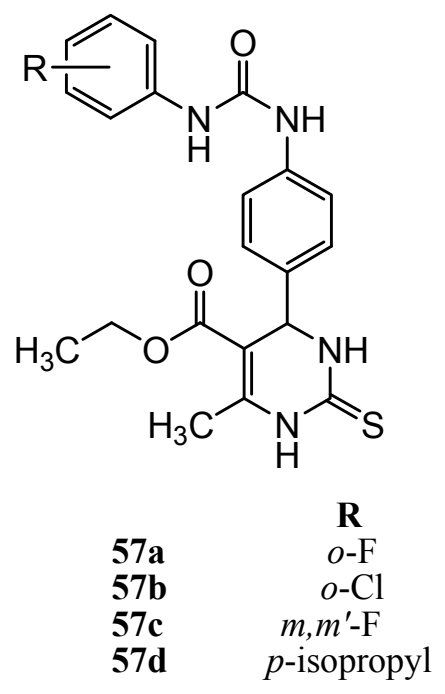

Figure 62. 1,2,3,4-THPMs having a substituted urea on the C-4 phenyl group

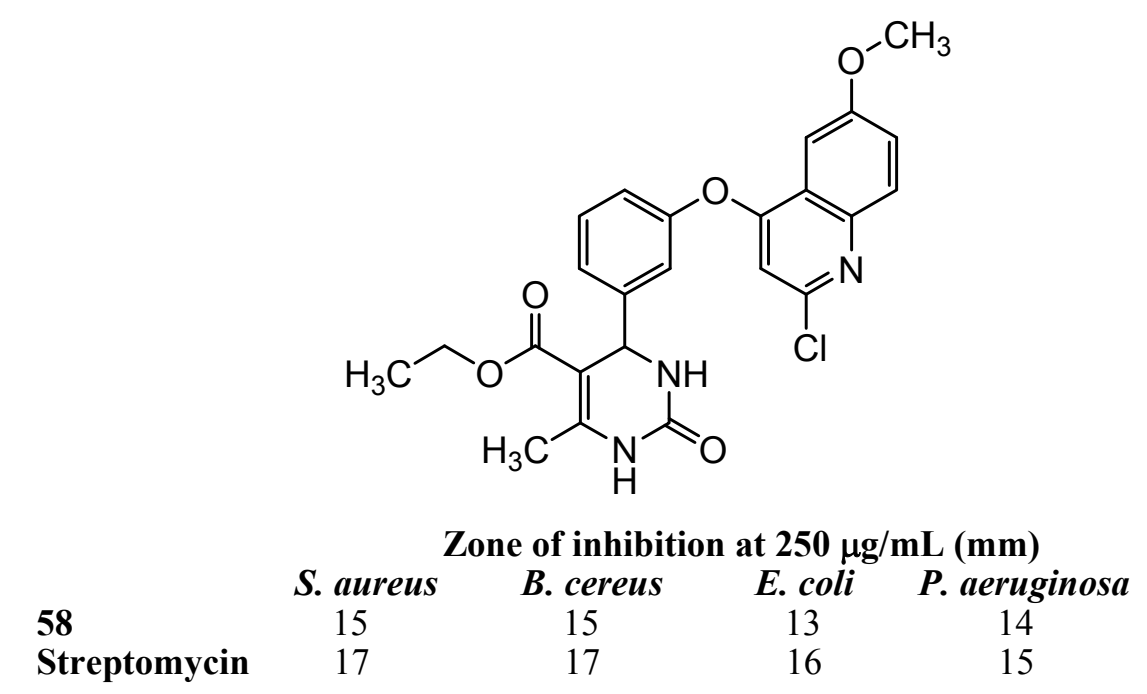

Figure 63. Chemical structure and antimicrobial activity of $\mathbf{5 8}$<smiles>CCOC(=O)C1=C(C)NC(=O)NC1c1ccc2ccc(OC)cc2c1</smiles>

59

Figure 64. 1,2,3,4-THPM containing a naphthalene ring at the C-4 position 
Adhikari et al. explained the antimicrobial activity of THPMs substituted by quinoline at C-4 position. These compounds were all stronger than the naphthalene analogues and showed moderate to good antimicrobial activities. Compound $\mathbf{6 0}$ showed good activity against $E$. coli, $P$. aeruginosa, $S$. aureus, C. albicans and A. flavus with zones of inhibition of $20,19,16,18$ and 20 (all at 100 $\mu \mathrm{g} / \mathrm{mL}$ ), respectively (Figure 65). The corresponding values for the standard drug (Chloramphenicol) were 19, 18, 16, 20 and 21 (all at the same concentration), respectively (127).<smiles>CCOC(=O)C1=C(C)NC(=S)NC1c1cc2ccccc2nc1O</smiles>

60

Figure 65. 1,2,3,4-THPM containing a quinoline moiety at the $\mathrm{C}-4$ position

Two 1,2,3,4-tetrahydropyrimidin-2(1H)-one (thione) scaffolds attached through a phenylene linker were also investigated by Chellakili et al. as possible antimicrobial compounds. They connected two tetrahydropyrimidine rings from their C-4 positions through a phenyl ring. These compounds showed good inhibitory activity against the growth of a wide variety of the microorganisms. Compound $\mathbf{6 1}$ shown in Figure 66 is an example of this series (128).

Arylamide derivatives of the 1,2,3,4tetrahydropyrimidine-2(1H)-one-5-carboxylic acid scaffold were also subjected to antimicrobial evaluations. Baldev et al. reported a series of compounds with this scaffold and claimed that very few of the compounds were less active than standard drugs (129) Figure 67. Substitution on the arylamide moiety was methyl, methoxy or halide in this research.

Sedaghati et al. prepared carboxylate ester and arylcarboxamide derivatives of the THPM ring with bulky substitutions containing heteroaromatic moieties at C-4 position of the ring. This heteroaromatic moiety was a substituted imidazole or a simple thienyl or furyl ring. Of note was the observation that the antimicrobial THPMs investigated in this research were stronger antifungals rather antibacterial agents. For example, 62a and 62b, which are shown in Figure 68, inhibited the fungal growth at lower concentrations (130).<smiles>CC1=C(C(=O)OC(C)C)NC(=S)NC1c1ccc(C2NC(=S)NC(C(=O)OC(C)C)=C2C)cc1</smiles>

\begin{tabular}{lcccc} 
& \multicolumn{5}{c}{ MIC $(\mu \mathrm{g} / \mathbf{m L})$} \\
$\mathbf{6 1}$ & B. subtilis & K. pneumonia & A. niger & C. albicans \\
Ciprofloxacin & 12.5 & 6.25 & 25 & 25 \\
Fluconazole & 12.5 & 12.5 & - & - \\
& - & - & 12.5 & 25
\end{tabular}

Figure 66. Two 1,2,3,4-tetrahydropyrimidin-2(1H)-thione scaffolds attached through a phenylene linker and the corresponding antimicrobial activities 
<smiles>[R]c1ccc(NC(=O)C2=C(C)NC(=O)NC2c2ccc(COc3ccccc3)cc2)cc1</smiles>

Figure 67. Arylamide derivatives of 1,2,3,4-THPMs possessing antimicrobial activity

Maddila et al. provided a series of pyrimidine derivatives fused to a thiazolidinone ring. These compounds were screened against gram-negative bacteria (E. coli and $P$. aeruginosa), gram-positive bacteria (B. subtillis and $S$. aureus) and fungi $(C$. albicans and $A$. niger). All the molecules displayed moderate to good antibacterial and antifungal activity. The halogenated and amino derivatives exhibited higher potency (131) Figure 69.

The same research group reported molecules which could be considered acyclic analogues of the above compounds. The antibacterial screening data revealed that all the tested compounds showed moderate to good bacterial inhibition. Compound
64 exerted ZIs of 25, 20, 29, 23 and $18 \mathrm{~mm}$ at 6.5 $\mu \mathrm{g} / \mathrm{mL}$ concentration against $E$. coli, $S$. aureus, $P$. aeruginosa, $S$. pyogenes and $K$. pneumonia, respectively (Figure 70). The corresponding data for Ciprofloxacin, used as the standard, were 30, 24, 33, 25 and $23 \mathrm{~mm}$, respectively, at the same concentration,. The prepared compounds were also screened for their antifungal activity and proved to be moderate to good antifungals against a wide variety of fungi. For instance, 64 emerged as a strong compound against $A$. flavus, A. fumigatus, $C$. albicans, Penicillium marneffei and Trichophyton mentagrophytes, with zones of inhibition (in millimeters) of 22, 22, 20, 22 and 25 at $6.5 \mu \mathrm{g} / \mathrm{mL}$, respectively (Amphotericin: 21, 25, 19, 25 and 23 at the same concentration, respectively) (132).

Other thiazolo[3,2-a]pyrimidine derivatives have been shown to possess significant antimicrobial activity. Compound 65a, for example, had ZI at $100 \mu \mathrm{g} / \mathrm{mL}$ of 16,14 and $15(\mathrm{~mm})$ against $B$. cereus, S. aureus and E. coli, respectively. Compound 65b demonstrated strong antifungal activity against $C$. albicans (Zone of inhibition at $100 \mu \mathrm{g} / \mathrm{mL}=15 \mathrm{~mm})$. The zones of inhibition at $100 \mu \mathrm{g} / \mathrm{mL}$ for the reference drug, Tetracycline, were $21 \mathrm{~mm}$ against $B$. cereus and $S$. aureus and 22 against $E$. coli. Miconazole inhibited $C$. albicans growth with a $19 \mathrm{~mm}$ zone of inhibition at 100 $\mu \mathrm{g} / \mathrm{mL}$ (133) Figure 71.<smiles>[R][X]C(=O)C1=C(C)NC(=O)NC1c1cnc(SC)n1Nc1ccccc1</smiles>

\begin{tabular}{|c|c|c|c|c|c|c|}
\hline & \multirow[b]{2}{*}{$\mathbf{R}$} & \multicolumn{4}{|c|}{ MIC $(\mu \mathrm{g} / \mathrm{mL})$} \\
\hline & & & E. coli & S. aureus & A. niger & C. albicans \\
\hline $62 \mathbf{a}$ & $\mathrm{NH}$ & $4-\mathrm{ClC}_{6} \mathrm{H}_{4}$ & 512 & $>512$ & 64 & 32 \\
\hline $62 b$ & $\mathrm{O}$ & $\mathrm{C}_{2} \mathrm{H}_{5}$ & 256 & $>512$ & 128 & 64 \\
\hline \multicolumn{3}{|c|}{ Ciprofloxacin } & 0.25 & 0.5 & - & - \\
\hline \multicolumn{3}{|c|}{ Ketoconazol } & - & - & 4 & 2 \\
\hline
\end{tabular}

Figure 68. Chemical structure and antimicrobial activity of 62a and 62b 
Nagarajaiah et al. reported an antimicrobial activity for thiazolo[3,2-a]pyrimidines with no substitution on the thiazolo part of the fused ring against $S$. aureus, E. coli and C. albicans that was similar to that of Gentamicin and Nystatin (134) (Figure 72).

Akbari et al. explained the antimicrobial activity of arylcarboxamide derivatives of thiazolo[3,2-a]pyrimidines by the fact that pyrimidine analogues (such as compound 67) possessed higher antimicrobial activity than thiazolopyrimidines (compound 68) due to the free $\mathrm{C}=\mathrm{S}$ group (135) (Figure 73).
The antibacterial and antifungal activities of carbohydrazide derivatives of THPMs were investigated in 2012. When they were screened against the gram negative bacteria $E$. coli and $P$. aeruginosa, the gram positive bacteria $B$. subtilis and $S$. aureus and two fungal organisms, A. niger and $C$. albicans, the molecules revealed weak activity against all bacterial strains, while compounds 69a and 69b showed good activity against $A$. niger and $C$. albicans, respectively (136) Figure 74 .<smiles>[R]c1ccc(/C=c2\sc3n(c2=O)C(c2ccc(-c4cccc(C(=O)OCC)c4)cc2)C(C(=O)OCC)=C(C)N=3)cc1</smiles>

\begin{tabular}{|c|c|c|c|c|c|c|}
\hline & \multicolumn{6}{|c|}{ 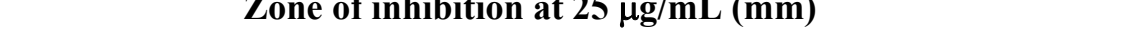 } \\
\hline $\mathbf{R}$ & E. coli & P. aeruginosa & B. subtilis & S. aureus & C. albicans & A. niger \\
\hline$p-\mathrm{Cl}$ & 13.16 & 12.15 & 13.42 & 14.60 & 11.48 & 12.16 \\
\hline 63b $\quad p-\mathrm{N}\left(\mathrm{CH}_{3}\right)_{2}$ & 14.72 & 11.79 & 14.18 & 13.07 & 13.44 & 11.23 \\
\hline Streptomycin & 12.78 & 13.36 & 12.14 & 15.39 & - & - \\
\hline Amphotericin-B & - & - & - & - & 12.89 & 14.89 \\
\hline
\end{tabular}

Figure 69. Antimicrobial activity of pyrimidine derivatives fused to a thiazolidinone ring<smiles>CCOC(=O)C1=C(C)NC(SCCc2ccccc2)=NC1c1ccc(-c2cccc(C(=O)OCC)c2)cc1</smiles>

Figure 70. Chemical structure of 64

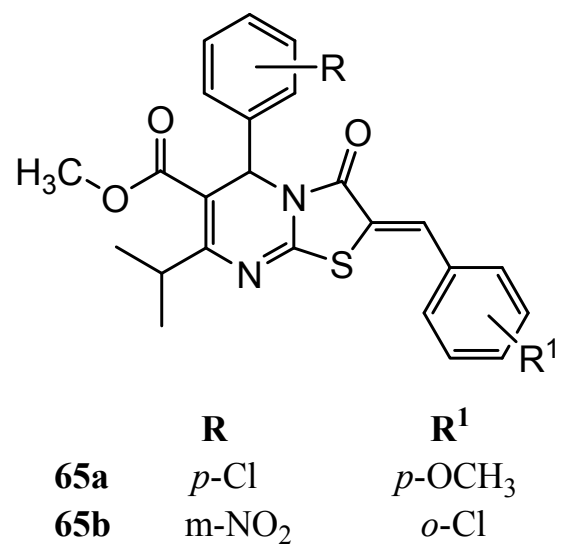

Figure 71. Chemical structures of some thiazolo[3,2a]pyrimidines 
<smiles>[R]c1ccc(C2C(C(=O)OCC)=C(C)N=C3SC=CN32)cc1</smiles>

\begin{tabular}{|c|c|c|c|}
\hline \multirow[b]{2}{*}{$R$} & \multicolumn{3}{|c|}{ Zone of inhibition at $50 \mu \mathrm{g} /$ disc $(\mathrm{mm}$} \\
\hline & E. coli & C. albicans & S. aureus \\
\hline $\mathrm{OCH}_{3}$ & 15 & 15.66 & - \\
\hline $\mathrm{OH}$ & - & - & 18 \\
\hline Gentamicin $(10 \mu \mathrm{g} /$ disc $)$ & 26 & - & 30 \\
\hline Nystatin $(10 \mu \mathrm{g} / \mathrm{disc})$ & - & 26 & - \\
\hline
\end{tabular}

Figure 72. Antimicrobial activity of thiazolo[3,2-a]pyrimidines

67

68

Ciprofloxacin

Griseofulvin<smiles>CC1=C(C(=O)Nc2ccc(Cl)cc2)C(c2cccc([N+](=O)[O-])c2)NC(=S)N1</smiles>

67<smiles>CC1=C(C(=O)Nc2ccc(Cl)cc2)C(c2cccc([N+](=O)[O-])c2)N2CCSC2N1</smiles>

68

Zone of inhibition at $200 \mu \mathrm{g} / \mathrm{mL}(\mathrm{mm})$

$\begin{array}{lcccc}\text { S. aureus } & \text { S. epidermidis } & \text { E. coli } & \text { P. aeruginosa } & \text { C. albicans } \\ 22.9 & 26 & 20 & 24.5 & 22.5 \\ 21.2 & 18.5 & 17.5 & 20 & 22 \\ 30 & 26 & 21 & 28 & - \\ 28 & 22 & 23 & 27 & 23\end{array}$

Figure 73. Antimicrobial activity of arylcarboxamide derivatives of 1,2,3,4-THPMs and thiazolo[3,2-a]pyrimidines<smiles>[X]C1=NC(C)=C(C(=O)NNC(=O)COc2ccc(NC(C)=O)cc2)C(c2ccc(O)cc2)N1</smiles>

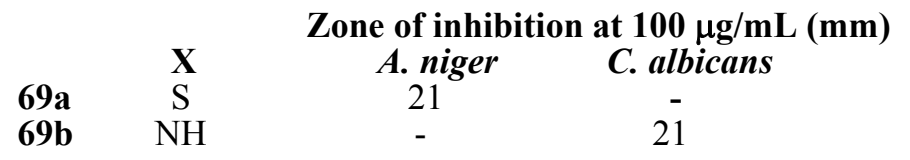

Figure 74. Antifungal activities of carbohydrazide derivatives of 1,2,3,4-THPMs 
Other hydrazide derivatives have shown a range of antimicrobial activities against gram positive and gram negative bacteria (Figure 75). Strong electronwithdrawing atoms $(\mathrm{F}, \mathrm{Cl})$ were responsible for the good activity of the molecules. Among the compounds reported, 70a and 70b were more potent than Norfloxacin (137).

Some more complicated carbohydrazide derivatives of THPMs were tested by Alsharifi et al. in 2012 for their antimicrobial activity. The results indicated that some of these compounds exhibit good fungicidal and antibacterial activity (138) Figure 76.

Compounds 72a and 72b shown in Figure 77 with a heteroaromatic ring at the $\mathrm{C}-5$ position of the tetrahydropyrimidine scaffold showed promising antibacterial activity against Streptococcus pneumonia and E. coli (mean ZI of $15 \mathrm{~mm}$ for both) compared with standard drugs Ofloxacin (mean $\mathrm{ZI}=19 \mathrm{~mm}$ ) and Levofloxacin (mean $\mathrm{ZI}=16 \mathrm{~mm}$ ). The presence of $\mathrm{NO}_{2}$ and $\mathrm{OCH}_{3}$ at para position of the $\mathrm{C}-4$ moiety was responsible for providing this good antibacterial activity to the molecules (139).<smiles>[R]c1ccc(C2NC(=S)NC(C)=C2C(=O)NNC(=O)c2ccncc2)cc1</smiles>

\begin{tabular}{lccc} 
& & \multicolumn{3}{c}{ MIC $(\mu \mathrm{mol} / \mathbf{m L})$} \\
& $\mathbf{R}$ & B. subtilis & E. coli \\
70a & $p-\mathrm{Cl}$ & 0.0111 & 0.0120 \\
$\mathbf{7 0 b}$ & $p-\mathrm{F}$ & 0.0112 & 0.0119 \\
Norfloxacin & 0.0124 & 0.0237
\end{tabular}

Figure 75. Chemical structures and antibacterial activities of 70a and 70b

71

Miconazole Amphotericin<smiles>CC1=C(C(=O)NN2c3nn(-c4ccccc4)c(-c4ccccc4)c3SC2c2ccc3c(c2)OCO3)C(c2ccccc2)NC(=O)N1</smiles>

$\operatorname{MIC}(\mu \mathrm{g} / \mathrm{mL})$

\section{B. subtilis E. coli S. aueus P. picketti}

$\begin{array}{lllll}71 & 26.24 & 17.60 & 20.35 & 22.25\end{array}$

$\begin{array}{lllll}\text { Tetracyclie } & 23 & 14 & 17.85 & 18.50\end{array}$

Zone of inhibition at $1000 \mathrm{ppm}(\%)$

$\begin{array}{cccccc}\text { T. longifusus } & \text { C. albicans } & \text { A. flavus } & \text { M. canis } & \text { F. solani } & \text { C. glabrata } \\ 88 & 72 & 78 & 61 & 79 & 91 \\ 90 & 90 & 90 & 90 & 90 & 90 \\ 90 & 90 & 90 & 90 & 90 & 90\end{array}$

Figure 76. Chemical structure and antimicrobial activities of 71 
Recently, Elumalai et al. evaluated the antimicrobial activities of the acetazolamide cyclocondensed 1,2,3,4-tetrahydropyrimidines shown in Figure 78. All the compounds displayed potent antimicrobial activity. Compounds containing $p$-chlorophenyl or $p$-fluorophenyl moiety at the $\mathrm{C}-4$ position and $\mathrm{S}$ or $\mathrm{O}$ atoms at the $\mathrm{C}-2$ of the dihydropyrimidine ring showed antibacterial activity against both gram positive (B. subtilis) and gram negative (E. coli) bacteria (140).

El-Fattah et al. investigated the antimicrobial activity of some C-5 unsaturated ketone derivatives of the THPM scaffold. These compounds were seen to have weak to moderate antimicrobial activity, with $\mathbf{7 4}$ showing the highest activity against all the tested strains, with zones of $7,10,10,9,12,11,8$ and $10 \mu \mathrm{mm}$ at $100 \mu \mathrm{g} / \mathrm{mL}$ against E. coli, $S$. typhimurium, L. monocytogenes, $S$. aureus, $P$. arginosus, B. cereus, C. albicans and A. flavus, respectively. Tobramycin $(10 \mu \mathrm{g} / \mathrm{mL})$, which was used as standard antibacterial, showed zones of inhibition of 20,18,20,19,18 and $19 \mathrm{~mm}$ against E. coli, S. typhimurium, L. monocytogenes, $S$. aureus, $P$. aeruginosa and $B$. cereus, respectively. Flucanazole $(25 \mu \mathrm{g} / \mathrm{mL})$, which was used as standard antifungal, had zones of inhibition $=17$ and $16 \mathrm{~mm}$ against $C$. albicans and A. flavus, respectively (141) Figure 79.

An unusual C-5 substitution on the 1,2,3,4tetrahydropyrimidine scaffold (Figure 80) led to weak antifungal and antibacterial compounds (142).

\section{ANTICANCER ACTIVITY}

In the search for novel anticancer drugs 1,2,3,4tetrahydropyrimidine derivatives have also been considered as promising cytotoxic agents. Among these compounds, 76a possessed specific cytotoxicity against colon carcinoma cells. Compounds $\mathbf{7 6 b}$ and $\mathbf{7 6}$ croved to be noncytotoxic inhibitors of carcinogen metabolic activators (Cyp), inducers of glutathione-Stransferase (GST) activity, scavengers of ${ }^{\bullet} \mathrm{OH}$ and $\mathrm{ROO}^{\bullet}$; and inhibitors of DNA fragmentation. They can therefore be regarded as active anti-initiation and multi-potent tumor blocking agents (143) Figure 81 .<smiles>[R]c1ccc(C2NC(=O)NC(C)=C2c2nnc(-c3ccccc3)o2)cc1</smiles>

Figure 77. 1,2,3,4-THPMs with heteroaromatic ring at the $\mathrm{C}-5$ position of the scaffold<smiles>[R]C/C=C\CC1NC([X])NC(C)=C1C(=O)NS(=O)(=O)c1nnc(NC(C)=O)s1</smiles>

\begin{tabular}{lcccc} 
& & & \multicolumn{2}{c}{ MIC $(\mu \mathrm{mol} / \mathbf{m L})$} \\
& $\mathbf{X}$ & $\mathbf{R}$ & B. subtilis & E. coli \\
73a & O & Cl & 0.0129 & 0.0134 \\
73b & S & F & 0.0114 & 0.0121 \\
Norfloxacin & & 0.0128 & 0.0132
\end{tabular}

Figure 78. Antimicrobial activities of the acetazolamide cyclocondensed 1,2,3,4-THPMs 
<smiles>COc1ccc(C2NC(=O)NC(C)=C2C(=O)/C=C/c2ccc(C)o2)cc1OC</smiles>

74

Figure 79. Chemical structure of an 1,2,3,4-THPM containing unsaturated ketone moiety at $\mathrm{C}-5$<smiles>CCON(CC)C(=O)C1=C(C)NC(=O)NC1c1ccc(O)cc1</smiles>

Zone of inhibition at $250 \mu \mathrm{g} / \mathrm{mL}(\mathrm{mm})$ 75 Ciprofloxacin S. aureus 0

Figure 80. Chemical structure and antibacterial activity of compound of $\mathbf{7 5}$

Chromone derivatives, which also possess anticancer activities, were introduced into the structure of cytotoxic THPMs, while Raju et al. explained the cytotoxicity of a series of $4 \mathrm{H}$ chromen-1,2,3,4-tetrahydropyrimidine-5carboxylate derivatives against three different human cancer cell lines (144). Compound 72 shown in Figure 82, with a cytotoxicity percentage of 47.6, 56 and 60.6 against lung (A549), CNS (SK-N_SH) and cervical (Hela) cancer cell lines was more effective than the standard drug, Doxorubicin (cytotoxicity percentage $=55.0,31.8$ and 86.5 against A549, SK-N_SH and Hela, respectively) (145). This compound was the most active amongst the studied compound.

The anticancer activity of a series of THPMs against human breast cancer (MCF-7) and colon

cancer (HCT 116) cell lines was reported in 2012. Amongst the studied compounds, molecules 78a and $\mathbf{7 8 b}$ were found to be the most effective against MCF-7 and HCT-116, respectively (Figure 83). 78a had an $\mathrm{IC}_{50}$ of $2.5 \mu \mathrm{g} / \mathrm{mL}$ while the standard drug, 5-fluorouracil (5-FU) had an $\mathrm{IC}_{50}$ of $0.67 \mu \mathrm{g} / \mathrm{mL}$ against MCF-7. $\mathbf{7 8 b}$, with an $\mathrm{IC}_{50}$ of $5 \mu \mathrm{g} / \mathrm{mL}$, was more potent than 5 -FU $\left(\mathrm{IC}_{50}=6 \mu \mathrm{g} / \mathrm{mL}\right.$ against HCT-116). According to a structure-activity investigation, the presence of the electronwithdrawing group on the phenylamino moiety was the enhancing factor in the anticancer activity of the synthesized compounds against HCT-116. On the other hand electron-releasing groups located on the phenylamino moiety increased the anticancer activity against the MCF-7 cancer cell line. Also, the existence of an oxo moiety at the C-2 position of the tetrahydropyrimidine ring improved the anticancer activity against both tested cell lines, although a thioxo moiety did not significantly improve the anticancer activity (146).

Prashantha Kumar et al. reported the in vitro anticancer activity of a series of 5-arylcarboxamide Biginelli pyrimidines against MCF-7 human breast cancer cells. Compounds with a cinnamoyl moiety at the C-4 position of the THPM ring (79a and 79b) exhibited major activity against MCF-7 cell lines. The presence of furan and pyridine moieties at the same position provided potential anticancer activity to the compounds (79c, 79d and 79e). Based on 3DQSAR studies, it was concluded that the 1,2,3,4tetrahydropyrimidine scaffold was the basic requirement for the cytotoxicity of this class of compounds (147) Figure 84.

THPMs with a substituted pyrazole at C-4 position were also subjected to in vitro anticancer activity evaluation against the MCF-7 cell line. Excellent inhibition of MCF-7 growth $(70.6 \%$ and $63.7 \%$ ) at $10 \mu \mathrm{M}$ concentration was observed for $\mathbf{8 0 a}$ and 80c, respectively. Structure-activity relationship studies revealed that compounds containing thioxo moiety at $\mathrm{C}-2$ position were more potent than the oxo analogues, which contrasts with the observations of Sharma et al. concerning the SAR of these compounds (146). The SAR results also revealed that the compounds with chlorine $(\mathrm{Cl})$ at $\mathrm{R}^{1}$ in the series $(\mathbf{8 0 a}, \mathbf{8 0 b}$ and $\mathbf{8 0 c}$ ) were more potent than compounds with no substitution at this position (80d). The structures of the compounds are illustrated in Figure 85. 
<smiles>COC(=O)C1=C(C)NC(=O)NC1c1ccc(C#N)cc1</smiles><smiles>[X]C1=NC(c2ccccc2)C(C(=O)OCC)=C(C)N1</smiles>

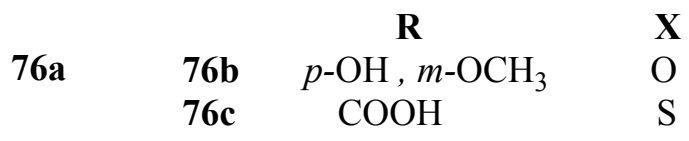

Figure 81. Chemical structures of anticancer tetrahydropyrimidine carboxylate esters<smiles>CCOC(=O)C1=C(C)NC(=O)NC1c1coc2c([N+](=O)[O-])cccc2c1=O</smiles>

Figure 82. 1,2,3,4-THPM containing chromone moiety at C-4 position<smiles>CCOC(=O)C1=C(C)NC(=O)NC1c1cn(C(=O)CNc2ccccc2N)c2ccccc12</smiles>

$78 \mathbf{a}$<smiles>CCOC(=O)C1=C(C)NC(=O)NC1c1cn(C(=O)CNc2ccc([N+](=O)[O-])c(Cl)c2)c2ccccc12</smiles>

$78 b$

Figure 83. Chemical structures of 78a and $\mathbf{7 8 b}$ 
<smiles>[X]C1NC(C)=C(C(=O)Nc2ccccc2Cl)C([R])N1</smiles>

$\begin{array}{lllc} & \mathbf{R} & \mathbf{X} & \text { \% Cytotoxicity } \\ \text { 79a } & \text { Cinnamoyl } & \text { S } & 71 \\ \text { 79b } & \text { Cinnamoyl } & \text { O } & 79 \\ \text { 79c } & \text { Furan-2-yl } & \text { S } & 76 \\ \text { 79d } & \text { Furan-2-yl } & \text { O } & 69 \\ \text { 79e } & \text { Pyridin-4-yl } & \text { S } & 72\end{array}$

Figure 84. Anticancer activity of some 5-arylcarboxamide Biginelli pyrimidines against MCF-7<smiles>[R]C(=O)C1=C(C)NC([X])NC1c1cn(-c2ccccc2)nc1-c1ccc([R1])cc1</smiles>

$\begin{array}{ccccc} & \mathbf{X} & \mathbf{R}^{\mathbf{1}} & \mathbf{R}^{\mathbf{2}} & \mathbf{G I}_{\mathbf{5 0}}(\boldsymbol{\mu M}) \\ \mathbf{8 0 a} & \mathrm{S} & \mathrm{Cl} & \mathrm{OC}_{2} \mathrm{H}_{5} & 33.2 \\ \mathbf{8 0 b} & \mathrm{S} & \mathrm{Cl} & p-\mathrm{CH}_{3} \mathrm{C}_{6} \mathrm{H}_{4} \mathrm{NH} & 43.5 \\ \mathbf{8 0 c} & \mathrm{O} & \mathrm{Cl} & p-\mathrm{CH}_{3} \mathrm{OC}_{6} \mathrm{H}_{4} \mathrm{NH} & 69.7 \\ \mathbf{8 0 d} & \mathrm{O} & \mathrm{H} & p-\mathrm{CH}_{3} \mathrm{OC}_{6} \mathrm{H}_{4} \mathrm{NH} & -\end{array}$

Figure 85. Chemical structures and anticancer activity of 1,2,3,4-THPMs with a substituted pyrazole at C-4 position

These results also suggest that replacing the alkyl ester moiety $\left(\mathrm{R}^{2}\right)$ with lipophilic carbamoyl influences the $\mathrm{GI}_{50}$ values against MCF-7 breast cancer cells (13).

Desai et al. investigated the correlation between anticancer activity against different cancer cell lines of several substituted 1,2,3,4-tetrahydropyrimidine derivatives and molecular descriptors based on quantitative structure-activity relationships. Weak correlation was observed between the physicochemical parameters and anticancer activity against leukemia, lung, and colon cancer cell lines, and a very good correlation between the descriptors and anticancer activity in the case of a breast cancer cell line. The results suggested that less lipophilic, less bulky and electron-withdrawing substituents may increase the potency against the breast cancer cell line. A positive influence of lipophilic and electronic parameters and a negative influence of steric parameters was observed when descriptors were correlated with anticancer activity against a prostate cancer cell line. The correlation between the activity against the CNS cancer cell line and molecular descriptors showed that decreasing the lipophilicity and electron density while increasing the bulk of the substituent will increase the potency (148).

The cytotoxicity activity of some 5arylcarboxamide THPMs against Vero cells has also reported (149). Weak to high cytotoxicity was claimed for the compounds with the general structure of Figure 86: 


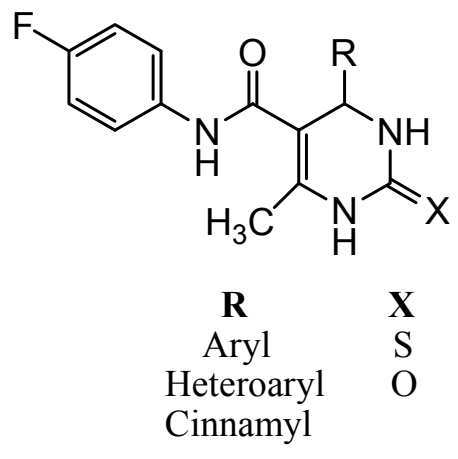

Figure 86. Arylamide derivatives of 1,2,3,4-THPMs possessing anticancer activity

Tetrahydropyrimidinone derivatives have been suggested as human kinesin Eg5 inhibitors. Monastrol (ethyl 4-(3-hydroxyphenyl)-6-methyl-2thioxo-1,2,3,4-tetrahydropyrimidine-5-carboxylate) is known as a low molecular weight, cell-permeable molecule, and has inspired a research line for the development of potentially new anticancer drugs (150) Figure 87.<smiles>CCOC(=O)C1=C(C)NC(=S)NC1c1cccc(O)c1</smiles>

Monastrol

Figure 87. Chemical structure of Monastrol

This compound specifically affects cell division (mitosis) by means of a mechanism that does not involve the binding to tubulin, unlike the natural Vinca and Taxane alkaloids and Epothilones. It has been established that the activity of Monastrol is based on the specific and reversible inhibition of the motility of mitotic kinesin Eg5, a motor protein required for bipolar spindle formation during mitosis $(151,152)$. Investigations showed that Monastrol was more potent than its deoxy derivative; therefore, the hydroxyl group in the aromatic ring is essential for the cytotoxic activity. However, the presence of the hydroxyl group seems not to be the best option, as can be observed orthomethoxy, para-methoxy and meta and paramethylenedioxy, substituents were all more potent than Monastrol (153) Figure 88.

Soumyanarayanan et al. screened the cytotoxic activity of compounds and suggested that compounds 81a and 81b (Figure 89) were the most potent against the $\mathrm{HepG} 2$ cell line, with $\mathrm{IC}_{50}=124$ and $120 \mu \mathrm{g} / \mathrm{mL}$, respectively. They also introduced 81a as the most potent compound against the Hela cell line $\left(\mathrm{IC}_{50}=187 \mu \mathrm{g} / \mathrm{mL}\right)$. Based on the biological results, it was anticipated that substitution of electron-withdrawing substituents, such as chlorine, at the para position of the C-4 phenyl ring may be essential for the ligand-receptor interaction. SAR analysis revealed that compounds with weakly basic pyrrolidine and piperidine substitutions in the C-5 side chain of these THPMs reduce the anticancer activity. In contrast, morpholine was not tolerated at this position and hence resulted in a decrease in $\mathrm{IC}_{50}$. Modeling the molecular interactions of these compounds with kinesin Eg5 protein revealed that the positioning of a hydrogen bond donor/acceptor on the C-4 phenyl ring plays a critical role in the inhibition of this enzyme (154).

\section{CONCLUSIONS AND PERSPECTIVES}

A detailed study of 1,4-dihydropyridine and 1,2,3,4tetrahydropyrimidine scaffolds points to some remarkable structural features that mark them as potential lead compounds for chemotherapeutic applications.

The nature of the groups substituted at C-3, C-4 and $\mathrm{C}-5$ positions of $1,4-\mathrm{DHPs}$ proved to be important for antitubercular, antimicrobial and anticancer activities of the derivatives of this scaffold. The structures of the active derivatives confirm that the lipophilicity of the molecule is an important physicochemical property that affects potency. An adequate degree of lipophilicity seems to be necessary for the chemotherapeutic properties of the compounds. 
<smiles>CCOC(=O)C1=C(C)NC(=S)NC1c1ccccc1</smiles>

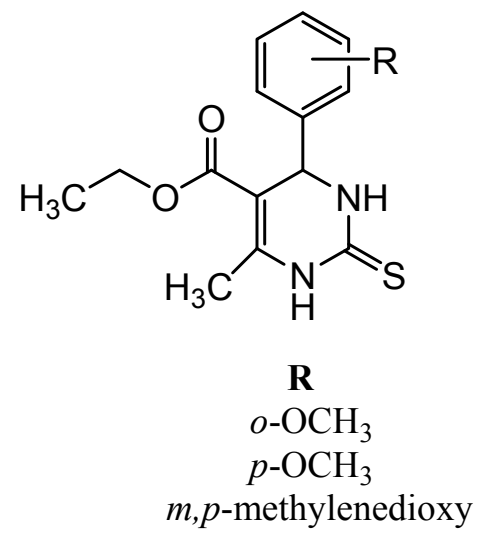

Figure 88. Structures of some anticancer 1,2,3,4-THPM carboxylate esters

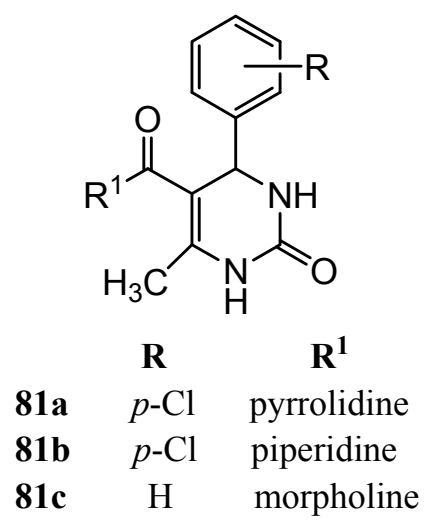

Figure 89. 1,2,3,4-THPMs with pyrrolidine and piperidine substituents in the $\mathrm{C}-5$ side chain

The presence of bulk substituents at C-3 and C5 positions of 1,4-DHPs, whether aromatic or heteroaromatic, increases the chemotherapeutic potency. Chain substitution at both positions also leads to antimycobacterial and antimicrobial compounds that are as potent as heteroaromatic substituted 1,4-DHPs.

Asymmetric 1,4-DHPs bearing both a carboxylate ester group and a carboxamide moiety, as well as symmetric DHPs with carboxylate ester groups in both $\mathrm{C}-3$ and $\mathrm{C}-5$ positions, represent potent antitubercular agents. Asymmetric 3,5dicarboxamide 1,4-dihydropyridines with two different dicarboxamide derivatives were seen to be weaker antitubercular agents than symmetric DHPs. Both symmetric and asymmetric compounds with at least one bulk group were seen to have effective cytotoxicity.
The C-4 substituent has a determinant effect on antitubercular, antimicrobial and anticancer activities. In almost all the reported 1,4dihydropyridines, the C-4 substituent is a (substituted) phenyl ring. Substitution on this ring is important for the antitubercular, antifungal, antibacterial and MDR-inhibiting activities. Replacement of the phenyl ring in C-4 position by heteroaromatic rings leads to compounds with high antitubercular, antimicrobial and anticancer activities. The substitution of medium-length (up to six carbons) aliphatic chains or cycloaliphatic groups at C-4 may provide key information about the SAR of this position.

$\mathrm{N}-1$ substitution of 3,5-phenylcarboxamide and 3,5-alkylcarboxylate esters of 1,4-DHPs decreases both the antitubercular and antimicrobial potency of the compound.

Aromatic pyridine derivatives have not yet been investigated for their antitubercular and antibacterial activities. Investigation into the effect of aromatization on these biological properties is recommended. Aromatized Hanztsch pyridines were anticancer agents as potent as 1,4dihydropyridines.

The C-2 and C- 6 positions have not been subjected to SAR studies. Alterations of the substitutents at these positions and exploring the effect of the hydrophobic/hydrophilic nature and also the steric limitations of these substituents will increase our knowledge of the structural requirements for chemotherapeutic properties of the compound.

As regards the structural and biological similarities between 1,4-dihydropyridines and 1,2,3,4-tetrahydropyrimidins described above, most 
of the conclusions provided for the structureactivity relationship are applicable to Biginelli THPMs.

Antitubercular, antimicrobial and anticancer activities are affected by the properties of the C-2, C-4 and C-5 substituents of 1,2,3,4-THPMs. Here again, bulk and lipophilic substituents, whether aromatic or heteroaromatic, increase the chemotherapeutic potency.

Oxo or thioxo atoms substituted on the $\mathrm{C}-2$ position of the 1,2,3,4-tetrahydropyrimidine both exist in the structure of the active compounds. Lipophilic substitutents at this position lead to improved antibacterial activity. Such substituents should also be investigated for antitubercular and anticancer derivatives.

Evaluation of other lipophilic moieties aliphatic, cycloaliphatic, aromatic or heteroaromatic - located at N-3 and N-1 positions is recommended.

The importance of the C-4 substituent concerning its chemotherapeutic properties is the same as that deduced in the case of 1,4-DHPs. Again, medium-length (up to six carbons) aliphatic chains or cycloaliphatic groups substituted at C-4 are worthy of further investigation for their structure-activity relationships.

Most of the 1,2,3,4-THPMs studied for their potential antitubercular activity bear C-5 carboxamide moieties, although carboxylate ester derivatives proved to be potent antitubercular agents. Thus, there seems to be a need for more investigation into carboxylate ester derivatives. Conversely, carboxamide derivatives need to be investigated more for their antimicobial properties. Both carboxamide and carboxylate ester derivatives have been confirmed as potent anticancer agents.

Alterations of the substitutents at C- 6 position will develop the knowledge of structurechemotherapeutic properties relationships established for 1,2,3,4-tetrahydropyrimidine scaffold.

The aromatization of Biginelli pyrimidines does not seem to add to their antitubercular properties and perhaps needs more investigation. The possible effect of this structural change on antitubercular and anticancer activity of the compounds needs to be clarified.

Determination of exact targets for the antitubercular, antimicrobial and anticancer properties of 1,4-dihydropyridines and 1,2,3,4tetrahydropyrimidines will pave the way for the rational structure-based design of novel chemotherapeutic derivatives. To the best of our knowledge, there are only two reports of modeling the molecular interactions of chemotherapeutically active 1,4-DHPs. In the first of these, Mycobacteriun tuberculosis enoyl reductase as a possible target for the antimycobacter 1,4dihydropyridine-3,5-dicarboxamides was subjected to molecular docking and molecular dynamics simulation studies. The second report was a molecular docking study of anticancer 1,4dihydropyridines in MRP1-NBD1 protein. Molecular interactions of 1,2,3,4tetrahydropyrimidines were modeled against human kinesin Eg5 protein for Monastrol, the FDA approved anticancer agent (154).

Among the ligand-based computer aided drug design approaches, the QSAR and 3D-QSAR methods provide valuable information about the structural features of the biologically active molecules (QSAR) and the binding features (3DQSAR) of their possible targets. Only a few QSAR studies concerning anticancer 1,4-DHPs, antimicrobial and anticancer 1,2,3,4-THPMs are available in the literature. The same is true for the 3D-QSAR studies. Antitubercular 1,4-DHPs, antitubercular and antimicrobial 1,2,3,4-THPMs have only been submitted to 3D-QSAR investigations. The lack of such research is obvious in the field of chemotherapeutic 1,4-DHP and 1,2,3,4-THPM compounds.

Thus, there is a clear need for computer-aided investigations to determine biological target(s) among those possibly present in the biochemical pathways involved, and for specific laboratory assays to experimentally determine such target(s). The structural features of the biologically active compounds and the binding features of their target active sites also need clarification.

\section{ACKNOWLEDGMENT}

This work was partially supported by the Fundación Séneca de la Región de Murcia under Project 18946/JLI/13.

\section{REFERENCES}

1. Biginelli P. Aldehyde-urea derivatives of aceto- and oxaloacetic acids. Gaz Chim Ital, 1893; 23: 360-413.

2. Hantzsch A. Ueber die synthese pyridinartiger verbindungen aus 
acetessigather

und

aldehydammoniak. Justus Liebigs Ann Chem, 1882; 215: 1-82.

3. Ulloora S, Kumar S, Shabaraya R, Adhikari AV. New dihydropyridine derivatives: anti-inflammatory, analgesic and docking studies. Med Chem Res, 2013; 22 (4): 1549-1562.

4. Radwan MA, Ragab EA, Sabry NM, ElShenawy SM. Synthesis and biological evaluation of new 3-substituted indole derivatives as potential anti-inflammatory and analgesic agents. Bioorg Med Chem, 2007; 15 (11): 3832-3841.

5. Kawase M, Shah A, Gaveriya H, Motohashi N, Sakagami H, Vargae A, Molnar J. 3,5Dibenzoyl-1,4-dihydropyridines: synthesis and MDR reversal in tumor cells. Bioorg Med Chem, 2002; 10: 1051-1055.

6. Morshed S, Hashimoto K, Murotani Y, Kawase M, Shah A, Satoh K, Kikuchi H, Nishikawa H, Maki J, Sakagamih H. Tumorspecific cytotoxicity of 3,5-dibenzoyl-1,4dihydropyridines. Anticancer Res, 2005; 25: 2033-2038.

7. Klein E, DeBonis S, Thiede B, Skoufias DA, Kozielski F, Lebeau L. New chemical tools for investigating human mitotic kinesin Eg5. Bioorg Med Chem, 2007; 15: 6474-6488.

8. Rucins M, Kaldre D, Pajuste K, Fernandes MAS, Vicente JAF, Klimaviciusa L, Jaschenko E, Kanepe-Lapsa I, Shestakova I, Plotniece M, Gosteva M, Sobolev A, Jansone B, Muceniece R, Klusa V, Plotniece A. Synthesis and studies of calcium channel blocking and antioxidant activities of novel 4pyridinium and/or N-propargyl substituted 1,4-dihydropyridine derivatives. C R Chim, 2014; 17 (1): 69-80.

9. Stefani HA, Oliveira CB, Almeida RB, Pereira CMP, Braga RC, Cell R, Borges VC, Savegnago L, Nogueira CW. Dihydropyrimidin- $(2 H)$-ones obtained by ultrasound irradiation: a new class of potential antioxidant agents. Eur $\mathrm{J}$ Med Chem, 2006; 41: 513-518.

10. Ulloora S, Shabaraya R, Ranganathan R, Adhikari AV. Synthesis, anticonvulsant and anti-inflammatory studies of new 1,4dihydropyridin-4-yl phenoxyacetohydrazones. Eur J Med Chem, 2013; 70: 341-349.
11. Bahekar SS, Shinde DB. Synthesis and antiinflammatory activity of some [4,6-(4substituted aryl)-2-thioxo-1,2,3,4tetrahydropyrimidin-5-yl]-acetic acid derivatives. Bioorg Med Chem Lett, 2004; 14: 1733-6.

12. Fassihi A, Azadpour Z, Delbari N, Saghaie L, Memarian HR, Sabet R, Alborzi A, Miri R, Pourabbas B, Mardaneh J, Mousavi P, Moeinifard B, Sadeghi-Aliabadi H. Synthesis and antitubercular activity of novel 4substituted imidazolyl-2,6-dimethyl- $\mathrm{N}^{3}, \mathrm{~N}^{5}-$ bisaryl-1,4-dihydropyridine-3,5-

dicarboxamides. Eur J Med Chem, 2009; 44: 3253-3258.

13. Yadlapalli RK, Chourasia OP, Vemuri K, Sritharan M, Perali RS. Synthesis and in vitro anticancer and antitubercular activity of diarylpyrazole ligated dihydropyrimidines possessing lipophilic carbamoyl group. Bioorg Med Chem Lett, 2012; 22: 27082711.

14. Yamamoto $\mathrm{T}$, Niwa $\mathrm{S}$, Ohno $\mathrm{S}$, Onishi $\mathrm{T}$, Matsueda H, Koganei H, Uneyama H, Fujita S, Takeda T, Kito M, Ono Y, Saitou Y, Takahara A, Iwata S, Shoji M. Structureactivity relationship study of 1,4dihydropyridine derivatives blocking N-type calcium channels. Bioorg Med Chem Lett, 2006; 16(4): 798-802.

15. Kshirsagar SS, Shanmugasundaram P. Synthesis and calcium channel blocking activity of 1, 2, 3, 4,-tetrahydropyrimidine derivatives containing carbamates and carbamides. Int J Chem Tech Res, 2013; 5(6): 2899-2912.

16. Barrow JC, Nantermet PG, Selnick HG, Glass KL, Rittle KE, Gilbert KF, Steele TG, Homnick CF, Freidinger RM, Ransom RW, Kling P, Reiss D, Broten TP, Schorn TW, Chang RSL, O'Malley SS, Olah TV, Ellis JD, Barrish A, Kassahun K, Leppert P, Nagarathnam D, Forray C. In vitro and in vivo evaluation of dihydropyrimidinone C-5 amides as potent and selective $\alpha_{1 \mathrm{~A}}$ receptor antagonists for the treatment of benign prostatic hyperplasia. J Med Chem, 2000; 43: 2703-2718.

17. Murthy YLN, Rajack A, Ramji MT, Jeson babu J, Praveen Ch, Lakshmi KA. Design, solvent free synthesis and antimicrobial 
evaluation of 1,4-dihydropyridines. Bioorg Med Chem Lett, 2012; 22: 6016-6023.

18. Ashok M, Holla BS, Kumari NS. Convenient one pot synthesis of some novel derivatives of thiazolo[2,3-b]dihydropyrimidinone possessing 4-methylthiophenyl moiety and evaluation of their antibacterial and antifungal activities. Eur J Med Chem, 2007; 42: 380-385.

19. Janis RA, Silver P, Triggle DJ. Drug action and cellular calcium. Adv Drug Res, 1987; 16: 309-591.

20. Khanina EL, Siliniece G, Ozols J, Duburs G, Kimenis A. Synthesis and pharmacological studies of some 1,2,3,4-tetrahydropyrimidine5-carboxylic acid derivatives. Khim Farm Zh, 1978; 12: 72-4.

21. Eisner U, Kuthan J. Chemistry of dihydropyridines. Chem Rev, 1972; 72 (1): 142.

22. Stout DM, Meyers AI. Recent advances in the chemistry of dihydropyridines. Chem Rev, 1982; 82 (2): 223-243.

23. Kastron VV, Vitolin RO, Dubur GY. Synthesis and pharmacological activity of 1,4-dihydropyridines. Pharm Chem J, 1990; 24 (6): 394-403.

24. Sausins AE, Duburs G. Synthesis of 1,4dihydropyridines in cyclocondensation reactions. Chem Heterocycl Compd, 1992; 28 (4): 363-391.

25. Sausin'sh A, Dubur G. Reactions of 1,4dihydropyridines. Chem Heterocycl Compd, 1993; 29 (5): 489-520.

26. Kappe CO. 100 years of the biginelli dihydropyrimidine synthesis. Tetrahedron, 1993; 49 (32): 6937-6963.

27. Kappe CO. Recent advances in the Biginelli dihydropyrimidine synthesis. New tricks from an Old Dog. Acc Chem Res, 2000; 33 (12): 879-888.

28. Lavilla R. Recent developments in the chemistry of dihydropyridines. J Chem Soc, 2002; 1: 1141-1156.

29. Eynde JJV, Mayence A. Synthesis and aromatization of Hantzsch 1,4dihydropyridines under microwave irradiation. An overview. Molecules, 2003; 8: 381-391.

30. Saini A, Kumar S, Sandhu JS. Hantzsch reaction: recent advances in Hantzsch 1,4- dihydropyridines. J Sci Indust Res, 2008; 67: 95-111.

31. Vdovina SV, Mamedov VA. New potential of the classical Biginelli reaction. Russ Chem Rev, 2008; 77: 1017-1053.

32. Shen L, Cao S, Wu J, Zhang J, Li H, Liu N, Qian X. A revisit to the Hantzsch reaction: unexpected products beyond 1,4dihydropyridines. Green Chem, 2009; 11: 1414-1420.

33. Mihaela M, Cristian D, Niculina DB, Daniel PF. Recent developments in the reactivity of the Biginelli compounds. Curr Org Synth, 2011; 8(18): 356-373.

34. Wan JP, Liua Y. Recent advances in new multicomponent synthesis of structurally diversified 1,4-dihydropyridines. RSC Adv, 2012; 2: 9763-9777.

35. Heravi MM, Asadi S, Malekzadeh Lashkariani B. Recent progress in asymmetric Biginelli reaction. Mol Divers, 2013; 17: 389-407.

36. Odynets AG, Simkhovich BZ, Kimenis AA, Ya Dubur G. Pharmacological effects and mechanism of action for preparations of the 1,4-dihydropyridine series on the cardiovascular system. Pharm Chem J, 1986; 20 (12): 822-829.

37. Campbell KP, Leung AT, Sharp AH. The biochemistry and molecular biology of the dihydropyridine-sensitive calcium channel. TINS, 1988; 11(10): 425-430.

38. Triggle DJ, Rampe D. 1,4-Dihydropyridine activators and antagonists: structural and functional distinctions. TiPS, 1989; 101: 507511.

39. Ohashi K, Ebihara A. Aranidipine (MPC1304), a new dihydropyridine calcium antagonist: a review of its antihypertensive action. Cardiovasc Drug Rev, 1996; 14(1): 116.

40. Testa R, Leonardi A, Tajana A, Riscassi E, Magliocca R, Sartani A. Lercanidipine (Rec 15/2375): a novel 1,4-dihydropyridine calcium antagonist for hypertension. Cardiovasc Drug Rev, 1997; 15: 187-219.

41. Mukherjee R, Spinale FG. L-type calcium channel abundance and function with cardiac hypertrophy and failure: a review. J Mol Cell Cardiol, 1998; 30; 1899-1916.

42. Berkels R, Roesen R, Dhein S, Fricke U, Klaus W. Dihydropyridine calcium 
antagonist-induced modulation of endothelial function: a review. Cardiovasc Drug Rev, 1999; 17: 179-86.

43. Nayler WG. Review of preclinical data of calcium channel blockers and atherosclerosis. J Cardiovasc Pharm, 1999; 33: S7-11.

44. Snutch TP, Sutton KG, Zamponi GW. Voltage-dependent calcium channels-beyond dihydropyridine antagonists. Curr Opin Pharmacol, 2001; 1(1): 11-6.

45. Mason RP. Mechanisms of plaque stabilization for the dihydropyridine calcium channel blocker amlodipine: review of the evidence. Atherosclerosis, 2002; 165: 191199.

46. Triggle DJ. 1,4-Dihydropyridines as calcium channel ligands and privileged structures. Cell Mol Neurobiol, 2003; 23(3): 293-303.

47. Safak C, Simsek R. Fused 1,4dihydropyridines as potential calcium modulatory compounds. Mini Rev Med Chem, 2006; 6(7): 747-55.

48. Ioan P, Carosati E, Micucci M, Cruciani G, Broccatelli FS, Zhorov B, Chiarini A, Budriesi R. 1,4-Dihydropyridine scaffold in medicinal chemistry, the story so far and perspectives (Part 1): action in ion channels and GPCRs. Curr Med Chem, 2011; 18 (22): 4901-22.

49. Singh K, Arora D, Singh K, Singh S. Source genesis of dihydropyrimidinone calcium channel blockers: recent progress in structureactivity relationships and other effects. Mini Rev Med Chem, 2009; 9 (1): 95-106.

50. Swarnalatha G, Prasanthi G, Sirisha N, Madhusudhana Chetty C. 1,4Dihydropyridines: a multifunctional molecule- a review. Int J Chem Tech Res, 2011; 3: 75-89.

51. Grover D, Mokale SN, Shete MT. Dihydropyridine: a novel pharmacophore. Int J Pharm Erud, 2011; 1(2): 16-29.

52. Kappe CO. 4-Aryldihydropyrimidines via the Biginelli condensation: aza-Analogs of nifedipine-type calcium channel modulators. Molecules, 1998; 3(1): 1-9.

53. Kappe CO. Biologically active dihydropyrimidones of the Biginelli-type -a literature survey. Eur J Med Chem, 2000; 35: 1043-1052.

54. Carosati E, Ioan P, Micucci M, Broccatelli F, Cruciani G, Zhorov BS, Chiarini A, Budriesi
R. 1,4-Dihydropyridine scaffold in medicinal chemistry, the story so far and perspectives (Part 2): action in other targets and antitargets. Curr Med Chem, 2012; 19 (25): 4306-4323.

55. Vaisalini B, Rao NV, Harika BML, Desu PK, Nama S. A review on biological activities of dihydropyrimidinones/thiones. Int $\mathrm{J}$ Pharm Chem Res, 2012; 1 (4): 6-14.

56. Edraki N, Mehdipour AR, Khoshneviszadeh M, Miri R. Dihydropyridines: evaluation of their current and future pharmacological applications. Drug Discov Today, 2009; 14: 1058-1066.

57. Bossert F, Vater W. 1,4-Dihydropyridines-a basis for developing new drug. Med Res Rev, 1989; 9 (3): 291-324.

58. World Health Organization Tuberculosis, fact sheet.

http://www.who.int/mediacentre/factsheets/fs 104/en/index.html. Accessed March 2014.

59. Zhang Y, Post-Martens K, Denkin S. New drug candidates and therapeutic targets for tuberculosis therapy. Drug Discov Today, 2006; 11: 21-7.

60. Jadhav VB, Holla HV, Tekale SU, Pawar RP. Bioactive dihydropyrimidines: an overview. Der Chemica Sinica, 2012; 3(5): 1213-1228.

61. Manvar AT, Pissurlenkar RR, Virsodia VR, Upadhyay KD, Manvar DR, Mishra AK, Acharya HD, Parecha AR, Dholakia CD, Shah AK, Coutinho EC. Synthesis, in vitro antitubercular activity and 3D-QSAR study of 1,4-dihydropyridines. Mol Divers, 2010; 14(2): 285-305.

62. Trivedi A, Dodiya D, Dholariya B, Kataria V, Bhuva V, Shah V. Synthesis and biological evaluation of some novel 1,4dihydropyridines as potential antitubercular agents. Chem Biol Drug Des, 2011; 78(5): 881-886.

63. Desai B, Sureja D, Naliapara Y, Shah A, Saxena AK. Synthesis and QSAR studies of 4-substituted phenyl-2,6-dimethyl-3, 5-Bis- $N$ (substituted phenyl)carbamoyl-1,4dihydropyridines as potential antitubercular agents. Bioorg Med Chem, 2001; 9(8): 19931998.

64. Amini M, Navidpour L, Shafiee A. Synthesis and antitubercular activity of new N,N-diaryl4-(4,5-dichloroimidazole-2-yl)-1,4-dihydro- 
2,6-dimethyl-3,5 pyridinedicarboxamides. Daru, 2008; 16(1): 9-12.

65. Shafii B, Amini M, Akbarzadeh T, Shafiee A. Synthesis and antitubercular activity of $\mathrm{N}^{3}, \mathrm{~N}^{5}$-Diaryl-4-(5-arylisoxazol-3-yl)-1,4dihydropyridine-3,5-dicarboxamide. J Sci Islamic Republ Iran, 2008; 19(4): 323-328.

66. Gevariya H, Desai B, Vora V, Shah A. Synthesis of some new unsymmetrical 1,4dihydropyridine derivatives as potent antitubercular agents. Heterocycl Commun, 2001; 7(5): 167-72.

67. Khoshneviszadeh M, Edraki N, Javidnia K, Alborzi A, Pourabbas B, Mardaneh J, Miri R. Synthesis and biological evaluation of some new 1,4-dihydropyridines containing different ester substitute and diethyl carbamoyl group as anti-tubercular agents. Bioorg Med Chem, 2009; 17(4): 1579-1586.

68. Trivedi AR, Dodiya DK, Dholariya BH, Kataria VB, Bhuva VR, Shah VH. Synthesis and biological evaluation of some novel $\mathrm{N}$ aryl-1,4-dihydropyridines as potential antitubercular agents. Bioorg Med Chem Lett, 2011; 21(18): 5181-5183.

69. Sirisha K, Achaiah G, Reddy VM. Facile synthesis and antibacterial antitubercular, and anticancer activities of novel 1,4dihydropyridines. Arch Pharm Chem Life Sci, 2010; 343(6): 342-352.

70. Kharkar PS, Desai B, Gaveria H, Varu B, Loriya R, Naliapara Y, Shah A, Kulkarni VM. Three-dimensional quantitative structure-activity relationship of 1,4dihydropyridines as antitubercular agents. J Med Chem, 2002; 45(22): 4858-4867.

71. Mahnam K, Sadeghi A, Mohammadpour M, Fassihi A. Theoretical studies of 1,4dihydropyridine-3,5-dicarboxamides as possible inhibitors of Mycobacteriun tuberculosis enoyl reductase. Monatsh Chem, 2012; 143(1): 19-27.

72. Saga $T$, Yamaguchi K. History of antimicrobial agents and resistant bacteria. JMAJ, 2009; 52(2): 103-108.

73. Prakash O, Hussain K, Kumar R, Wadhwa D, Sharma C, Aneja KR. Synthesis and antimicrobial evaluation of new 1,4-dihydro4-pyrazolylpyridines and 4pyrazolylpyridines. Org Med Chem Lett, 2011; 1: 1-6.
74. Vijesh AM, Isloor AM, Peethambar SK, Shivananda KN, Arulmoli T, Isloor NA. Hantzsch reaction: synthesis and characterization of some new 1,4dihydropyridine derivatives as potent antimicrobial and antioxidant agents. Eur $\mathbf{J}$ Med Chem, 2011; 46(11): 5591-5597.

75. Maya JD, Morello A, Repetto Y, Tellez R, Rodriguez A, Zelada U, Puebla P, Caballero E, Medarde M, Nunez-Vergara LJ, Squella JA, Bonta M, Bollo S, Feliciano AS. Effects of 3-chloro-phenyl-1,4-dihydropyridine derivatives on trypanosome cruzi epimastigotes. Comp Biochem Phys C, 2000; 125: 103-109.

76. Ladani NK, Mungra DC, Patel MP, Patel RG. Microwave assisted synthesis of novel Hantzsch 1,4-dihydropyridines, acridine-1,8diones and polyhydroquinolines bearing the tetrazolo[1,5-a]quinoline moiety and their antimicrobial activity assess. Chinese Chem Lett, 2011; 22(12): 1407-1410.

77. Dabholkar VV, Rajaram PS, Vinod PR. Synthesis and biological evaluation of novel 1,4-dihydropyridine derivatives. Hetero Lett, 2011; 1: 275-279.

78. Gunduz MG, Ekizoglu M, Kart D, Simsek R, Safak C. Antimicrobial screening of 2methyl-3-acyl-4-aryl-2,6,6 and/or 2,7,7trimethyl-1,4,5,6,7,8-hexahydroquinoline derivatives. Hacettepe Uni J Faculty Pharm, 2011; 31: 51-58.

79. Akbarzadeh T, Motagian S, Tafti AF, Shafiee A, Shahverdi AR. Synthesis and the combination effects of dihydropyridine analogs with selected antibiotics against resistant Staphylococcus aureus. Res Pharm Sci, 2008; 3: 87-93.

80. Akbarzadeh T, Fallah Tafti A, Samadi N, Foroumadi A, Amanlou M, Faramarzi MA, Shafiee A. Synthesis and cloxacillin antimicrobial enhancement of 2methylsulfonylimidazolyl-1,4-

dihydropyridine derivatives. Daru, 2010; 18(2): 118-123.

81. Sirisha K, Bikshapathi D, Achaiah G, Reddy VM. Synthesis, antibacterial and antimycobacterial activities of some new 4aryl/heteroaryl-2,6-dimethyl-3,5-bis-N-(aryl)carbamoyl-1,4-dihydropyridines. Eur J Med Chem, 2011; 46(5): 1564-1571. 
82. Rao NS, Lakshmi K. Synthesis and antimicrobial activit of some 1,4dihydropyridines derivatives. Sci Revs Chem Commun, 2013; 3 (3): 141-149.

83. Kumar RS, Idhayadhulla A, Abdul Nasser AJ, Selvin J. Synthesis and antimicrobial activity of a new series of 1,4dihydropyridine derivatives. J Serb Chem Soc, 2011; 76 (1): 1-11.

84. Kumar RS, Idhayadhulla A, Manilal A. Synthesis and antimicrobial activity of some new 1,4-dihydropyridine derivatives. Int $\mathbf{J}$ Pharm World Res, 2011; 2: 1-17.

85. Solanki MJ, Vachharajani PR, Dubal GG, Shah VH. Synthesis and antimicrobial evaluation of some newer symmetrical 1,4dihydropyridines. Int $\mathrm{J}$ Chem Tech Res, 2011; 3: 1139-1144.

86. Samaunnisa AA, Venkataramana CHS, Madhavan V. Synthesis, characterization and biological evaluation of novel $\mathrm{N}^{3}, \mathrm{~N}^{5}-$ diphenyl-1,4-dihydropyridine-3,5-

dicarbohydrazide derivatives. Int J Res Pharm Chem, 2013; 3: 160-167.

87. Bhavsar H, Anand K, Patel B, Gudaparthi V, Parikh H. Synthesis and biological evaluation of some novel 1,4-dihydropyridine derivatives of drug potentials. Pharma Sci Monit, 2012; 3: 2786-2797.

88. Samaunnisa AA, Venkataramana CHS, Madhavan V. Synthesis, characterization and biological activity of novel derivatives of bis pyrazolidine-3,5-dione tethered with 1,4dihydropyridine moiety. Contemp Investigat Observ Pharm, 2013; 2: 36-42.

89. Abu-Melha H. Synthesis, antibacterial and antifungal evaluation of novel 1,4dihydropyridine derivatives. Spectrochim Acta A Mol Biomol Spectrosc, 2013; 113: 115-122.

90. Chhillar AK, Arya P, Mukherjee C, Kumar P, Yadav Y, Sharma AK, Yadav V, Gupta J, Dabur R, Jha HN, Watterson AC, Parmar VS, Prasad AK, Sharma GL. Microwave-assisted synthesis of antimicrobial dihydropyridines and tetrahydropyrimidin-2-ones: novel compounds against aspergillosis. Bioorg Med Chem, 2006; 14(4): 973-981.

91. Ahmed A, Molvi KI, Baig I, Nazim S, Sheikh AA. One Pot Synthesis of Certain Novel Substituted Analogous of 1,4Dihydropyridines and their Antimicrobial
Activities. Int J Drug Design Discov, 2013; 4(1): 978-982.

92. Rajput AP, Girase PD. Synthesis, characterization and microbial screening of isoxazole derivatives of 2,6-dichloro-1-(Nsubstituted phenyl)-1,4-dihydropyridine-3,5dicarbaldehyde. Int J Chem Res, 2011; 2: 3841.

93. Rajput AP, Girase PD. Synthesis, characterization and microbial screening of 4thiazolidinone derivatives of 2,6-dichloro-1(N-substituted phenyl)-1,4-dihydropyridine3,5-dicarbaldehyde. Int J Pharm Tech Res, 2011; 3: 2111-7.

94. Mithlesh, Pareek PK, Ravikant, Ojha KG. Synthesis and biological screening of 1,4dihydropyridine derivatives containing benzothiazolyl moiety. Der Pharma Chemica, 2011; 3: 66-79.

95. Rokad SV, Tala SD, Akbari JD, Dhaduk MF, Joshi HS. Synthesis, antitubercular and antimicrobial activity of some new $\mathrm{N}$-aryl1,4-dihydropyridines containing furan nucleus. J Indian Chem Soc, 2009; 86: 186191.

96. Kohno K, Kikuchi J, Sato S, Takano H, Saburi Y, Asoh K, Kuwano M. Vincristineresistant human cancer $\mathrm{KB}$ cell line and increased expression of multidrug-resistance gene. Jpn J Cancer Res, 1988; 79(11): 12381246.

97. Ferry DR, Russell MA, Cullen MH. Pglycoprotein possesses a 1,4-dihydropyridineselective drug acceptor site which is allosterically coupled to a vinca-alkaloidselective binding site. Biochem Biophys Res Commun, 1992; 188(1): 440-445.

98. Ecker G, Huber M, Schmid D, Chiba P. The importance of a nitrogen atom in modulators of multidrug resistance. Mol Pharm, 1999; 56 (4): 791-796.

99. Zamora JM, Pearce HL, Beck WT. Physicalchemical properties shared by compounds that modulate multidrug resistance in human leukemic cells. Mol Pharmcol, 1988; 33 (4): 454-462.

100. Tanabe H, Tasaka S, Ohmori H, Gomi N, Sasaki Y, Machida T, Iino M, Kiue A, Naito S, Kuwano M. Newly synthesized dihydropyridine derivatives as modulators of P-glycoprotein-mediated multidrug 
resistance. Bioorg Med Chem, 1998; 6 (11): 2219-2227.

101. Miri R, Mehdipour A. Dihydropyridines and atypical MDR: a novel perspective of designing general reversal agents for both typical and atypical MDR. Bioorg Med Chem, 2008; 16 (18): 8329-8334.

102. Zhou XF, Shao Q, Coburn RA, Morris ME. Quantitative structure-activity relationship and quantitative structure-pharmacokinetics relationship of 1,4-dihydropyridines and pyridines as multidrug resistance modulators. Pharm Res, 2005; 22(12): 1989-1996.

103. Ford JM, Halt WN. Pharmacology of drugs that alter multidrug resistance in cancer. Pharmacol Rev, 1990; 42 (3): 155-199.

104. Tasaka S, Ohmori $\mathrm{H}$, Gomi $\mathrm{N}$, Iino $\mathrm{M}$, Machida T, Kiue A, Naitob S, Kuwano M. Synthesis and structure-activity analysis of novel dihydropyridine derivatives to overcome multidrug resistance. Bioorg Med Chem Lett, 2001; 11(2): 275-277.

105. Zhou XF, Zhang L, Tseng E, Scott-Ramsay E, Schentag JJ, Coburn RA, Morris ME. New 4-aryl-1,4-dihydropyridines and 4arylpyridines as P-glycoprotein inhibitors. Drug Metab. Dispos, 2005; 33(3): 321-328.

106. Bazargan L, Fouladdel S, Shafiee A, Amini M, Ghaffari SM, Azizi E. Evaluation of anticancer effects of newly synthesized dihydropyridine derivatives in comparison to verapamil and doxorubicin on T47D parental and resistant cell lines in vitro. Cell Biol Toxicol, 2008; 24(2): 165-174.

107. Ali MA, Chowdhary MA, Nazim Uddin M. Four- and five-coordinate copper (II) complexes containing mixed ligands. Polyhedron, 1984; 3(5): 595-598.

108. Kumar RS, Idhayadhulla A, Abdul Nasser AJ, Murali K. Synthesis and anticancer activity of some new series of 1,4dihydropyridine derivatives. Indian J Chem, 2011; 50: 1140-1144.

109. Sirisha K, Shekhar MC, Umasankar K, Mahendar P, Sadanandam A, Achaiah G, Redd VM. Molecular docking studies and in vitro screening of new dihydropyridine derivatives as human MRP1 inhibitors. Bioor Med Chem, 2011; 19(10): 3249-3254.

110. Engi H, Sakagami H, Kawase M, Parecha A, Manvar D, Kothari H, Adlakha P, Shah A, Motohashi N, Ocsovszki I, Molnar J. Tumor- specific Cytotoxicity and MDR-reversal Activity of Dihydropyridines. In vivo, 2006; 20(5): 637-644.

111. Sarkarzadeh H, Miri R, Firuzi O, Amini M, Razzaghi-Asl N, Edraki N, Shafiee A. Synthesis and antiproliferative activity evaluation of imidazole-based indeno[1,2b]quinoline-9,11-dione derivatives. Arch Pharm Res, 2013; 36(4): 436-447.

112. Singh K, Singh K, Wan B, Franzblau S, Chibale K, Balzarini J. Facile transformation of Biginelli pyrimidin-2(1H)-ones to pyrimidines. In vitro evaluation as inhibitors of Mycobacterium tuberculosis and modulators of cytostatic activity. Eur J Med Chem, 2011; 46: 2290-2294.

113. Trivedi AR, Bhuva VR, Dholariya BH, Dodiya DK, Kataria VB, Shah VH. Novel dihydropyrimidines as a potential new class of antitubercular agents. Bioorg Med Chem Lett, 2010; 20(20): 6100-6102.

114. Trivedi A, Dodiya D, Surani J, Jarsania S, Mathukiya H, Ravat N, Shah V. Facile onepot synthesis and antimycobacterial evaluation of pyrazolo[3,4-d]pyrimidines. Arch Pharm Chem Life Sci, 2008; 341(7): 435-439.

115. Virsodia V, Pissurlenkar RR, Manvar D, Dholakia C, Adlakha P, Shah A, Coutinho EC. Synthesis, screening for antitubercular activity and 3D-QSAR studies of substituted N-phenyl-6-methyl-2-oxo-4-phenyl-1,2,3,4tetrahydro-pyrimidine-5-carboxamides. Eur $\mathrm{J}$ Med Chem, 2008; 43(10): 2103-2115.

116. Zalavadiya $\mathrm{P}$, Tala S, Akbari J, Joshi $\mathrm{H}$. Multi-component synthesis of dihydropyrimidines by iodine catalyst at ambient temperature and in vitro antimycobacterial activity. Arch Pharm Chem Life Sci, 2009; 342(8): 469-475.

117. Chikhale RV, Bhole RP, Patil PA, Khedekar PB, Bhusari KP. Synthesis and antimicrobial activity of some ethyl [6-methyl-2-methoxy3-(substituted phenylethanone)-4-(substituted phenyl)]-1,2,3,4-tetrahydropyrimidine-5carboxylates. Der Pharma Chemica, 2009; 1 (1): 247-257.

118. Sawant RL, Bhatia MS. Synthesis, screening and QSAR studies of 3-formyl-2-thioxo1,2,3,4-tetrahydropyrimidine analogues as antibacterial agents. Orient J Chem, 2008; 24: 181-188. 
119. Sawant RL, Bhatia MS. Synthesis, Screening and QSAR Studies of 3-benzoyl-2oxo/thioxo-1,2,3,4-tetrahydropyrimidine analogues as antibacterial agents. Bull Chem Soc Ethiop, 2008; 22 (3): 391-402.

120. Hussein MA, Abdel Moty SG, Abdel Aziz SA, Abou-Salim MA. Synthesis and antimicrobial activity of new substituted dihydropyrimidine derivatives. Bull Pharm Sci, Assiut University, 2011; 34: 37-52.

121. El-Hamouly WS, Amine KM, Tawfik HA, Dawood DH, Moharam ME. Synthesis and antimicrobial activity of new 3,4dihydropyrimidinones. IJPSR, 2011; 2 (4): 1054-1062.

122. Nagawade RR, Shinde DB. Synthesis and Anti-bacterial Activity of New Series of 4(Substituted biphenyl-4-yl)-6-methyl-2oxo/thioxo-1,2,3,4-tetrahydro-pyrimidine-5carboxylic Acid Ethyl Ester. J Heterocycl Chem, 2010; 47(1): 33-39.

123. Rani NS, Reddy GVS, Veera KNJ. Synthesis of new 4-aryl-3, 4-dihydropyrimidin-2(1H)ones/ thiones/ imines and their antimicrobial evaluation. J Chem Pharm Res, 2014; 6 (2): 373-379.

124. Tale RH, Rodge AH, Hatnapure GD, Keche AP. The novel 3,4-dihydropyrimidin-2(1H)one urea derivatives of $\mathrm{N}$-aryl urea: Synthesis, anti-inflammatory, antibacterial and antifungal activity evaluation. Bioorg Med Chem Lett, 2011; 21(15): 4648-4651.

125. Balaji GL, Rajesh K, Kouser Ali S, Vijayakumar V. Ultrasound-promoted synthesis of novel 2-chloroquinolin-4pyrimidine carboxylate derivatives as potential antibacterial agents. Res Chem Intermed, 2013; 39(4): 1807-1815.

126. Borse BN, Borude VS, Shukla SR. Synthesis of novel dihydropyrimidin-2(1H)-ones derivatives using lipase and their antimicrobial activity. Curr Chem Lett, 2012; 1(2): 59-68.

127. Adhikari A, Kalluraya B, Sujith KV, Gouthamchandra, Mahmood R. Synthesis, characterization and biological evaluation of dihydropyrimidine derivatives. Saudi Pharm, J 2012; 20(1): 75-79.

128. Chellakili B, Premalatha B, Gopalakrishnan M. Synthesis, spectral analysis, antimicrobial activity and molecular docking studies of 1,2,3,6-tetrahydropyrimidine-4-carboxylate.
Int J Pharm Sci Health Care, 2014; 2(4): 2249-5738.

129. Baldev AD, Vyas KB, Patel KB, Nimavat KS. Synthesis of 1,2,3,4-tetrahydro pyrimidine derivatives as an antimicrobial agent. J Chem Pharm Res, 2012; 4 (6): 29722978.

130. Sedaghati B, Fassihi A, Arbabi S, Ranjbar M, Memarian HR, Saghaie L, Omidi A, Sardari A, Jalali M, Abedi D. Synthesis and antimicrobial activity of novel derivatives of Biginelli pyrimidines. Med Chem Res, 2012; 21(12): 3973-3983.

131. Maddila S, Damu GLV, Oseghe E, Abafe A, Venakata Rao C, Lavanya P. Synthesis and biological studies of novel biphenyl-3,5dihydro- $2 H$-thiazolopyrimidines derivatives. J Korean Chem Soc, 2012; 56: 334-340.

132. Maddila S, Jonnalagadda SB. Synthesis and biological activity of ethyl 2-(substituted benzylthio)-4-(3'-(ethoxycarbonyl)biphenyl4-yl)-6-methyl-1,4-dihydropyrimidine-5 carboxylate derivatives. Arch Pharm Chem Life Sci, 2012; 345(2): 163-168.

133. Oza TD, Parikh A, Gudaparthi V. Synthesis and biological screening of some novel 3amino-4-arylidene-5-pyrazolones and thiazolo $[3,2-\mathrm{a}]$ pyrimidines. Pharma Sci Monitor, 2012; 3(4): 2775-2785.

134. Nagarajaiah H, Khazi IM, Begum NS. Synthesis, characterization and biological evaluation of thiazolopyrimidine derivatives. J Chem Sci, 2012; 124: 847-855.

135. Akbari JD, Kachhadia PK, Tala SD, Bapodra AH, Dhaduk MF, Joshi HS, Mehta KB, Pathak SJ. Synthesis of some new 1,2,3,4tetrahydropyrimidine-2-thiones and their thiazolo[3,2-a]pyrimidine derivatives as potential biological agents. Phosphorus Sulfur Silicon, 2008; 183(8): 1911-1922.

136. Basavaraja HS, Sadyojatha I, Shivakumar B, padamashali B,Vijay Kumar MMJ, Bharathi DR. Synthesis, QSAR and antimicrobial evaluation of some novel substituted tetrahydropyrimidine derivatives. Int J Pharm Chem Sci, 2012; 1: 319-325.

137. Elumalai K, Ashraf Ali M, Elumalai M, Eluri K, Srinivasan S. Novel isoniazid cyclocondensed 1,2,3,4-tetrahydropyrimidine derivatives for treating infectious disease: a synthesis and in vitro biological evaluation. $\mathrm{J}$ Acute Dis, 2013; 2 (4): 316-321. 
138. Alsharifi H, Patel HS. Synthesis, characterization and biological application of novel pyrozolone derivatives of 1,2dihydropyrimidone ring. Int $\mathrm{J}$ Sci Innovat Discove, 2012; 2 (4): 408-417.

139. Mishra MK, Gupta AK, Negi S, Bhatt M. Synthesis of some new oxadiazole with antimicrobial activity. Int J Pharma Sci Res, 2010; 1: 172-177.

140. Elumalai K, Ashraf Ali M, Elumalai M, Eluri K, Srinivasan S, Mohanty SK. Microwave assisted synthesis of some novel acetazolamide cyclocondensed 1,2,3,4tetrahydropyrimidines as a potent antimicrobial and cytotoxic agents. Benisuef University J Basic Appl Sci, 2014; 3(1): 2431.

141. El-Fattah OA, Abbas EMH, Ahmed N, Mohamed, Abd-Elmoez SI. Synthesis and evaluation of some tetrahydropyrimidine derivatives as antimicrobial. Australian J Bas Appl Sci, 2010; 4 (1): 27-36.

142. Shah DH, Sen DJ. Synthesis and antibacterial activity of some 4,5-disubstituted-6-Methyl1,2,3,4-Tetrahydropyrimidin-2(1H)-one derivatives. Int J Drug Develop Res, 2012; 4: 330-335.

143. Tawfik HA, Bassyouni F, Gamal-Eldeen AM, Abo-Zeid MA, El-Hamouly WS. Tumor antiinitiating activity of some novel 3,4dihydropyrimidinones. Pharmacol Rep, 2009; 61: 1153-1162.

144. Walenzyk T, Carola C, Buchholz H, Konig B. Chromone derivatives which bind to human hair. Tetrahedron, 2006; 61 (31): 7366-7377.

145. Raju BC, Rao RN, Suman P, Yogeeswari P, Sriram D, Shaik TB, Kalivendi SV. Synthesis, structure-activity relationship of novel substituted 4H-chromen-1,2,3,4tetrahydropyrimidine-5-carboxylates as potential anti-mycobacterial and anticancer agents. Bioorg Med Chem Lett, 2011; 21(10): 2855-2859.

146. Sharma SK, Kumar P, Narasimhan B, Ramasamy K, Mani V, Mishra RK, Abdul Majeed AB. Synthesis, antimicrobial, anticancer evaluation and QSAR studies of 6methyl-4-[1-(2-substituted-phenylaminoacetyl)-1H-indol-3-yl]-2-oxo/thioxo-1,2,3,4- tetrahydropyrimidine-5-carboxylic acid ethyl esters. Eur J Med Chem, 2012; 48: 16-25.

147. Prashantha Kumar BR, Sankar G, Nasir Baig RB, Chandrashekaran S. Novel Biginelli dihydropyrimidines with potential anticancer activity: A parallel synthesis and CoMSIA study. Eur J Med Chem, 2009; 44(10): 41924198.

148. Desai NC, Chhabaria MT, Dodiya A, Bhavsar AM, Baldaniya BB. Synthesis, characterization, anticancer activity, and QSAR-studies of some new tetrahydropyrimidines. Med Chem Res, 2011; 20(8): 1331-1339.

149. Elumalai K, Ashraf Ali M, Elumalai M, Eluri K, Srinivasan SS, Mohanthi SK, Kaleru P, Durraivel S. Synthesis, Characterisation and biological evaluation of novel Biginelli dihydropyrimidines. Der Pharmacia Lett, 2012; 4 (4): 1143-1148.

150. Mayer TU, Kapoor TM, Haggarty SJ, King RW, Schreiber SI, Mitchison TJ. Small molecule inhibitor of mitotic spindle bipolarity identified in a phenotype-based screen. Science, 1999; 268: 971-974.

151. Cochran JC, Gatial JE, Kapoor TM, Gilbert SP. Monastrol inhibition of the mitotic kinesin Eg5. J Biol Chem, 2005; 280(13): 12658-12667.

152. Peters T, Lindenmaier H, Haefeli WE, Weiss $\mathrm{J}$. Interaction of the mitotic kinesin $\mathrm{Eg} 5$ inhibitor monastrol with P-glycoprotein. J Weiss Arch Pharmacol, 2006; 372(4): 291299.

153. Russowsky D, Canto RFS, Sanches SAA, Doca MGM, Fatima A, Pilli RA, Kohn LK, Antonio MA, Carvalho JE. Synthesis and differential antiproliferative activity of Biginelli compounds against cancer cell lines: Monastrol, oxo-monastrol and oxygenated analogues. Bioorg Chem, 2006; 34(4): 173182.

154. Soumyanarayanan U, Bhat VG, Kar SS, Mathew JA. Monastrol mimic Biginelli dihydropyrimidinone derivatives: synthesis, cytotoxicity screening against HepG2 and HeLa cell lines and molecular modeling study. Org Med Chem Lett, 2012; 2: 23-33. 


\section{ABBREVIATIONS}

$\begin{array}{ll}\text { ABC } & \text { ATP-binding cassette } \\ \text { 1,4-DHP } & \text { 1,4-dihydropyridine } \\ \text { 3D-QSAR } & \text { 3D-quantitative structure-activity relationship } \\ \text { DXR } & \text { Doxorubicine } \\ \text { GST } & \text { Glutathione-S-transferase } \\ \text { MCR } & \text { Multi-component reaction } \\ \text { MDR } & \text { Multi-drug resistance } \\ \text { MRP1 } & \text { Multidrug resistance protein 1 } \\ \text { Pgp } & \text { P-glycoprotein } \\ \text { QSAR/QSPKR } & \text { Quantitative structure-activity/pharmacokinetics relationship } \\ \text { RS } & \text { Resistant cells } \\ \text { SAR } & \text { Structure-activity relationship } \\ \text { TB } & \text { Tuberculosis } \\ 1,2,3,4-T H P M & \text { 1,2,3,4-Tetrahydropyrimidine } \\ \text { TS } & \text { Tumor specific } \\ \text { VCR } & \text { Vincristine } \\ \text { VP } & \text { Verapamil } \\ \text { ZI } & \text { Zone of inhibition }\end{array}$

